\title{
EL ACOGIMIENTO RESIDENCIAL DE LOS MENORES CON PROBLEMAS DE CONDUCTA: UN INSTRUMENTO DE PROTECCIÓN DE MENORES CON INCIDENCIA EN LOS DERECHOS FUNDAMENTALES
}

\author{
The residential care of children with behavioural \\ problems: An instrument for the protection with \\ effect on fundamental rights
}

\author{
AURORA LÓPEZ AZCONA \\ Universidad de Zaragoza \\ alopaz@unizar.es
}

Cómo citar/Citation

López Azcona, A. (2018).

El acogimiento residencial de los menores con problemas de conducta: un instrumento de protección de menores con incidencia en los derechos fundamentales. Derecho Privado y Constitución, 32, 133-186. doi: https://doi.org/10.18042/cepc/dpc.32.04

(Recepción: 20/04/208. Aceptaciòn tras revisión: 05/06/2018. Publicación: 22/06/2018.

\section{Resumen}

La última y profunda reforma del sistema estatal de protección de infancia y adolescencia acaecida en 2015 ha dado entrada a un nuevo instrumento de protección de menores cuya incidencia en los derechos fundamentales consagrados en la Constitución española es más que notoria. Me refiero al acogimiento residencial en centros específicos, recurso con el que se trata de dar cobertura específica en el ámbito de la protección de la infancia a los menores con problemas de conducta. Sin dejar de defender la virtualidad de esta modalidad de acogimiento, una lectura detallada de los nuevos preceptos dedicados al mismo en la Ley Orgánica 1/1996 de Protección 
Jurídica del Menor (arts. 25 a 35) plantea no pocos problemas interpretativos a la luz de los derechos fundamentales. Resulta así muy dudosa ya no solo la delimitación legal del concreto colectivo de menores a que está reservado este acogimiento, sino la propia regulación del recurso de protección en sí mismo, desde el momento en que su finalidad educativa queda un tanto difuminada entre las medidas de restricción de derechos fundamentales susceptibles de adopción, singularmente en estos centros. Con todo, es de valorar muy positivamente la preocupación del legislador estatal de dotar a este instrumento de un importante elenco de garantías dirigidas a evitar su uso arbitrario.

\title{
Palabras clave
}

Acogimiento residencial; menores con problemas de conducta; centro de protección específico; derechos fundamentales.

\begin{abstract}
The last deep reform of the State system of protection of children in 2015 has brought a new instrument for the protection of minors whose impact on the fundamental rights enshrined in the Spanish Constitution is more than notorious. I refer to the residential placement in special protection centers for children with behavioural problems, resource which is meant to giving specific coverage in the field of the protection of "children with behavioural problems». While defending the virtuality of this sort of residential placement, the truth is that a detailed reading of the new precepts, dedicated to the same Organic Law 1/1996 of Legal Protection of the Minor (arts. 25-35) sets out quite a few interpretation problems in the light of fundamental rights. Therefore, it is very doubtful, not only the legal delimitation of the specific collective of minors to which this foster care is reserved, but the same regulation of the protection resource in itself, from the moment in which its educational purpose is somewhat blurred amongst the measures of restriction of fundamental rights susceptible of adoption singularly in these centers. However, the concern of the legislator to give this instrument an important range of safeguards to prevent its arbitrary use should very positively assessed.
\end{abstract}

\section{Keywords}

Residential care; children with behavioural problems; special protection centers; fundamental rights. 


\section{SUMARIO}

I. PREVIO: EL PREOCUPANTE INCREMENTO DE LOS MENORES CON PROBLEMAS DE CONDUCTA Y SU POSIBLE ETIOLOGÍA. II. LA NECESARIA ARTICULACIÓN DE RECURSOS INTERMEDIOS DE PROTECCIÓN. III. EL ACOGIMIENTO RESIDENCIAL DE MENORES CON PROBLEMAS DE CONDUCTA COMO ÚLTIMO INSTRUMENTO DE PROTECCIÓN: 1. Preliminares. 2. Tipología y subsiguiente oportunidad. 3. Principios rectores. 4. Destinatarios: 4.1. La noción legal y sus problemas interpretativos. 4.2. La importancia del diagnóstico. 4.3. La falta de previsión legal sobre la edad mínima para aplicar esta medida de protección. 5. Finalidad. 6. Medidas restrictivas de derechos fundamentales: 6.1. Medidas de seguridad. 6.2. Restricciones en el régimen de visitas y de comunicaciones con familiares y allegados y en los permisos de salida. 6.3. El régimen disciplinario. 7. Procedimiento para la adopción de esta medida: 7. 1. La necesaria autorización judicial. 7.2. Garantías reservadas al menor. 7.3. Garantías adicionales. 7.4. La necesaria ratificación judicial de los ingresos urgentes. 7.5. Régimen de recursos. 8. Supervisión y control. 9. Cese. BiblografíA.

\section{PREVIO: EL PREOCUPANTE INCREMENTO DE LOS MENORES CON PROBLEMAS DE CONDUCTA Y SU POSIBLE ETIOLOGÍA}

La última y profunda reforma del sistema estatal de protección de infancia y adolescencia acaecida en 2015 (LO 8/2015, de 22 de julio y Ley 26/2015, de 28 julio) ha dado entrada en el mismo a un nuevo instrumento de protección de menores cuya incidencia en los derechos fundamentales es más que notoria. Me refiero al acogimiento residencial en centros de protección específicos, recurso con el que se pretende proporcionar cobertura específica a un creciente colectivo como son los menores con problemas o trastornos de conducta ${ }^{1}$. A grandes rasgos, tal denominación viene referida a aquellos menores - adolescentes, habitualmente ${ }^{2}$ con graves problemas de adaptación a su entorno

1 De acuerdo con la Comisión especial del Senado de estudio de la problemática de la adopción nacional y otros temas afines (en adelante, Comisión especial del Senado); Acta de la sesión de 4 abril 2011: 2-3.

2 Especialmente aquellos que se encuentran en la adolescencia media, esto es, con edades comprendidas entre los 13 y los 17 años. Fuente: González-Álvarez et al. (2011: 18), Gó- 
familiar y social por comportamientos disruptivos o contraventores de las normas básicas de la convivencia y de los que pueden derivarse daños para su propio autor y/o para terceros (Vázquez-Pastor Jiménez, 2016:135). Estos comportamientos suelen manifestarse a través de agresiones verbales y/o físicas dentro de la familia —violencia filioparental—, el maltrato entre compañeros y hacia sus educadores — violencia escolar-, la indisciplina y el fracaso escolar, y la nula tolerancia a la frustración ${ }^{3}$. Este tipo de conductas, además de la tensión y aun riesgo que implica para terceros, interfiere en el adecuado desarrollo de la personalidad de los propios menores. Por añadidura, el trastorno de conducta puede conllevar importantes riesgos para la salud cuando viene acompañado - lo que no es infrecuente- del consumo habitual de alcohol y drogas ${ }^{4}$.

En cualquier caso, la expresión «trastorno de conducta» que se utiliza habitualmente para identificar a este colectivo de menores no puede inducir a error, porque los comportamientos disruptivos en que incurren no son fruto, en principio, de un trastorno mental, sino más bien el resultado de las denominadas «conductas aprendidas»y, por ende, susceptibles de modificación ${ }^{5}$. Así, los problemas de conducta suelen iniciarse con intentos de los menores de ejercer el control sobre sus progenitores. Si tienen éxito, las relaciones de poder se invierten progresivamente; en suma, según consiguen metas aumenta su agresividad, porque asumen que se apoderan del control familiar. El proceso en que se ven involucrados los progenitores es el inverso, en el sentido en que adoptan paulatinamente conductas de inhibición o, incluso, sumisión a sus hijos ${ }^{6}$. Es más, en buena parte de los casos estos comportamientos superan el ámbito familiar para extrapolarse a los entornos escolar — con la consiguiente incidencia negativa en su rendimiento académico- y social ${ }^{7}$. Como señala el propio preámbulo de la $\mathrm{LO} 8 / 2015$, de 22 de julio, de modificación del sistema de protección a la infancia y a la adolescencia (apdo. II.9), nos encontramos ante «situaciones muy conflictivas derivadas de problemas de comportamiento

mez Aparicio (2013: 280-281) y Observatorio de la Infancia en Andalucía (2012: 36). En cuanto al sexo de los menores, los estudiosos suelen coincidir en que este tipo de conductas son comunes a ambos sexos, si bien los varones suelen incurrir sobre todo en violencia física y las mujeres en violencia psicológica; por todos, Lozano Martínez et al. (2013: 240).

4 Comisión Interautonómica de Directores Generales de la Infancia (2010: 3). A nivel doctrinal se manifiestan en el mismo sentido, entre otros, Pereira Tercero et al. (2009: 4), González-Álvarez et al. (2011: 22-23) y Lozano Martínez et al. (2013: 241).

5 De acuerdo con Pereira Tercero (2009: 3) y Claver Turiégano (2017: 22).

6 Como señalan, entre otros, Aroca Montolío (2013: 13), March (2007: 217-218) y Pereira Tercero et al. (2009: 4).

7 Según advierte González-Álvarez et al. (2011: 21). 
agresivo, inadaptación familiar y social, situaciones de violencia filioparental y graves dificultades para ejercer la responsabilidad parental».

A partir de ahí, la etiología de estas conductas disociales es muy diversa, pero fundamentalmente obedece, a mi entender, a las deficiencias del proceso educativo de sus protagonistas ${ }^{8}$. Fallan los patrones educativos por erráticos, confusos y porque los progenitores han perdido sus habilidades en el contexto social y familiar actual ${ }^{9}$, evidenciando graves carencias y una desacertada combinación de conceptos, por extremadamente coercitivos y por sumamente permisivos, que a la larga provocan que el menor se desconcierte y rechace cualquier control. Este factor de riesgo se agrava cuando los estilos educativos de los progenitores son divergentes, lo que no es inhabitual en el caso de divorciados o separados que buscan la adhesión del menor. Ahora bien, el fenómeno aquí descrito no se encuentra exclusivamente asociado a las familias rotas ni a las desestructuradas. Por el contrario, provienen habitualmente de ambientes «normalizados» y de cualquier nivel sociocultural. Por añadidura, este tipo de problemática se ha visto favorecida por factores tales como el incremento de las familias con un hijo único y de las monoparentales, la cada día más avanzada edad para llegar a progenitores, la incorporación de la mujer al mundo laboral ausente de un reparto equitativo de responsabilidades familiares y el auge de modelos educativos sin equilibrio en el método de recompensa y sanción ${ }^{10}$.

Y cómo no, también está la reticencia de los progenitores a usar de su autoridad a raíz de la reforma del art. $154 \mathrm{CC}$ en virtud de la DF $1^{\text {a }}$ de la Ley 54/2007, de 28 de diciembre, de Adopción Internacional, con la quizá excesiva, por radical, supresión del derecho-deber de los progenitores a corregir razonada y moderadamente a sus hijos ${ }^{11}$ y su subsiguiente sustitución por la

8 Participa también de esta opinión Berrocal Lanzarot (2017: 277). Ahora bien, de acuerdo con March (2007: 217), no se puede negar la recíproca influencia entre los factores contextuales y biológicos, ello en el sentido de que cada individuo tiene un temperamento innato que ulteriormente será modulado por las influencias del ambiente en que se desenvuelva.

9 A tal respecto, March (2007: 2015) habla atinadamente de cuestionamiento de los modelos educativos, familiares y éticos hasta ahora válidos.

10 Sigo en este punto los datos proporcionados por la Fiscalía General del Estado (Circular 2010: 3) y, en la doctrina, por Pereira Tercero et al. (2009: 5-12), Aroca Montolío et al. (2012: 234-247), Berrocal Lanzarot (2017: 274-276) y Claver Turiégano (2017: 23).

11 Nótese, sin embargo, que esta facultad de corrección se encuentra presente en buena parte de los derechos civiles territoriales. En particular, es de valorar muy positivamente la fórmula adoptada por el art. 65 del Código del Derecho Foral de Aragón y por el art. 236-17 del Código Civil de Cataluña, en cuanto recogen como límites de este derecho-deber ya no solo la moderación y razonabilidad como el art. 63.1 del Fuero 
mera posibilidad de recabar el auxilio de la autoridad que, a mi entender, no parece muy eficaz en la práctica ${ }^{12}$. De esta forma, se ha privado a los progenitores de amparo legal explícito para imponer con moderación sanciones o medidas correctivas a sus hijos, lo que puede generar situaciones muy complicadas, porque paralelamente parece haberse relativizado la obediencia y respeto que los hijos deben a sus progenitores ex art. $155.1^{\circ} \mathrm{CC}^{13}$. Y dejo a salvo mi absoluto rechazo al menor atisbo de violencia y trato vejatorio de los progenitores hacia sus hijos como forma de ejercer la responsabilidad educativa que les incumbe ex art. $154.3 .1^{\circ} \mathrm{CC}$, por resultar atentatorio a la dignidad y la integridad física y mental de los menores, como advirtió en su momento la observación general núm. 8 (2006) del Comité de los Derechos del Niño de Naciones Unidas sobre el derecho del niño a la protección contra los castigos corporales y otras formas de castigo crueles o degradantes, en coherencia con lo dispuesto en el art. 37 de la Convención sobre los Derechos del Niño de $1989^{14}$.

Esta compleja problemática ha generado desde hace unos años la necesaria intervención de los poderes públicos en cumplimiento del mandato del art. 39.2 CE y del art. 11.1 LO 1/1996, de Protección Jurídica del Menor (en

Nuevo de Navarra, sino adicionalmente el pleno respeto a la dignidad de los hijos y la prohibición de imponer sanciones humillantes o atentatorias a sus derechos.

12 Como señalan, igualmente, Hurtado Yelo (2009: 4) y Pous de la Flor (2014: 1381 y 1385).

13 García Pérez (2018: 12) advierte a este respecto del contrasentido que supone haber privado a los padres de la facultad de corrección y, sin embargo, atribuirles la responsabilidad civil de los daños causados por sus hijos ex art. 1903.2 CC.

14 La observación general núm. 8 de Naciones Unidas (Naciones Unidas, Comité de los Derechos del Niño, 2006), complementada por las observaciones finales a España (Naciones Unidas, Comité de los Derechos del Niño, 2002), recomienda la supresión de la facultad de corrección de los progenitores contemplada en no pocos derechos nacionales, por entender que «tal tipo de disposición podía dar entrada a cierto grado de violencia contra los niños» y, por ende, vulnerar el art. 19 de la Convención sobre los Derechos del Niño de 1989. Esta apreciación, sin dejar de ser cierta, por lo que hace al ordenamiento jurídico español creo que debe matizarse, desde el momento en que en el Código Penal actualmente está tipificado como delito cualquier tipo de maltrato en el seno de la familia, ya sea ocasional (art. 153) o habitual (art. 173), lo que desautoriza en nuestro país el empleo de la más mínima violencia hacia a los hijos aun con finalidad correctora, tal y como advierte Boldova Pasamar (2011: 62). Con todo, como se ha indicado en texto, cuando el legislador español reformó en 2007 el art. 154 CC optó por excluir la facultad de corrección de entre los derechos-deberes integrantes de la patria potestad, invocando al respecto las referidas recomendaciones del Comité de los Derechos del Niño. 
adelante, LOPJM), a fin de prestar asistencia especializada a los menores que incurren en tales conductas en aquellos casos graves y extremos en que los progenitores no pueden cumplir sus deberes de guarda ${ }^{15}$. Nos encontramos así con un nuevo perfil de usuarios del sistema de protección de la infancia ${ }^{16}$, para el cual la LO 8/2015 ha articulado un último recurso de protección que radica en su ingreso en centros específicos en los que, a la par de su finalidad educativa, está prevista la aplicación de medidas de restricción de derechos fundamentales y de un régimen disciplinario. Así, dicha ley ha incorporado a los arts. 25 y ss. de la LO 1/1996 de Protección Jurídica del Menor una nueva modalidad de acogimiento como es el acogimiento residencial en centros de protección específicos de menores con problemas de conducta.

\section{LA NECESARIA ARTICULACIÓN DE RECURSOS INTERMEDIOS DE PROTECCIÓN}

Con carácter previo al análisis del instrumento de protección que da título al presente trabajo, no puedo dejar de hacer una apreciación, por lo demás, obvia: la importancia de la prevención de este tipo de comportamientos y la necesaria articulación de recursos intermedios encaminados a trabajar con las familias ante situaciones de riesgo, en la idea de que las intervenciones tempranas son más eficientes ${ }^{17}$. No ha sido esta, sin embargo, la opción del

15 Como advierte atinadamente Díez García (2010: 201-202 y 207), estamos en presencia de una nueva modalidad de intervención administrativa que, en principio, se justifica no en la conducta de los progenitores, sino en la de los propios menores, lo que dificulta su encaje en las situaciones hasta ahora contempladas en la legislación española como habilitantes de aquella, a saber: la situación de riesgo, la situación de desamparo y la situación de inasistencia provisional e inimputable que justifica la guarda administrativa.

16 De acuerdo con el Protocolo básico de actuación con menores en centros y/o residencias con menores diagnosticados de trastornos de conducta de la Comisión Interautonómica de Directores Generales de la Infancia (2010: 1) y el preámbulo de la LO 8/2015 (apdo. II.8).

17 Ya con anterioridad a la Ley 8/2015, la importancia de la prevención fue remarcada en las comparecencias de la Comisión especial del Senado (actas de las sesiones de 28 de marzo de 2011:27-28, de 4 de abril de 2011: 5 y 12, 17, y de 20 de abril de 2011: 22); y, a nivel doctrinal, por De Palma del Teso (2006: 171 y 177), March (2007: 215), Díez García (2010: 247-250) y Sainz-Cantero Caparrós (2014: 128). Sobre las posibles vías de intervención temprana, véase Observatorio de la Infancia en Andalucía (2012: 54-58). 
legislador estatal en $2015^{18}$, en cuanto se ha limitado a adoptar como última solución la separación del menor de su entorno familiar cuando la situación ya es insostenible a través de su ingreso en un centro de protección específico, haciendo caso omiso a las recomendaciones que el Comité de Ministros del Consejo de Europa y el Comité de los Derechos del Niño de Naciones Unidas dirigieron a España en 2005 y 2010 respectivamente, así como a las vertidas, a nivel nacional, por el Defensor del Pueblo en su informe sobre «Centros de protección de menores con trastornos de conducta y en situación de dificultad social» (Defensor del Pueblo, 2009), la Fiscalía General del Estado en su Circular 1/2010 y la Comisión especial del Senado de estudio de la problemática de la adopción nacional y otros temas afines $(2011)^{19}$. Se ha prescindido así de dar entrada en la LOPJM a la actuación protectora de la Administración en un plano preventivo ante tal problemática tan grave, a la par que se ha renunciado a ampliar la noción de «situación de riesgo» para incluir aquellas situaciones en que se manifiestan los primeros síntomas de problemas de conducta $^{20}$, lo que, a mi juicio, hubiera resultado muy conveniente, para así priorizar la intervención en el propio entorno sociofamiliar del menor ${ }^{21}$.

De este planteamiento difieren de modo plausible las leyes autonómicas de protección de menores que, aun circunscribiendo en su práctica totalidad el concepto de riesgo a aquellas situaciones en que se detecta un peligro para el menor generado por la falta de aptitudes de los progenitores en el desempeño de la guarda ${ }^{22}$, prevén el desarrollo de actuaciones preventivas por parte

18 Véase en términos igualmente críticos García Díez (2016: 4).

19 Comité de Ministros del Consejo de Europa (2005: apdo. I, regla 2), Comité de los Derechos del Niño de Naciones Unidas (2010: recomendación 42.e), Defensor del Pueblo (2009: 405), Fiscalía General del Estado (Circular 2010: 4) y Comisión especial del Senado (Informe de 21 de septiembre de 2011:163). En cualquier caso, esta omisión fue detectada por el Consejo Económico y Social (2014: 13) en fase de anteproyecto de 2014, sin que fuera subsanada ni en el proyecto de ley ni el texto definitivamente aprobado.

20 Como apuntó en su día Díez García (2010: 248) respecto a la legislación autonómica de protección de menores.

21 Y más cuando el art. 11.2 LOPJM enuncia entre los principios rectores de la intervención administrativa en materia de protección de menores tanto "el mantenimiento del menor en el medio familiar de origen salvo que no sea conveniente para su interés» (letra b), como «la prevención de todas aquellas situaciones que puedan perjudicar su desarrollo personal» (letra d). Coincide en esta valoración negativa García Díez (2016: 3-4).

22 Así resulta de la lectura del art. 22.1 de la Ley andaluza 1/1998, 12/2001, del art. 60.2 de la Ley balear 17/2006, del art. 50 de la Ley cántabra 8/2010, del art. 48 de la Ley 14/2002 de Castilla y León, del art. 102 de la Ley catalana 14/2010, del art. 45 
de la Administración en el seno de la familia, dirigidas fundamentalmente a reeducar al propio menor con el fin de modificar su comportamiento y contribuir a su socialización ${ }^{23}$, pero también a orientar a los progenitores en el adecuado ejercicio de sus funciones parentales ${ }^{24}$. Con todo, más allá de estas previsiones normativas, resulta fundamental que las comunidades autónomas se doten de programas específicos de intervención temprana que se activen cuando empiecen a manifestarse los primeros indicadores de que los progenitores están perdiendo el control sobre sus hijos, con la necesaria implicación de todos los sujetos afectados ${ }^{25}$. Más aún, abogaría por la elaboración a nivel estatal de un protocolo de intervención integral donde se articulasen recursos específicos especializados en los sistemas educativo, sanitario y de servicios sociales para impulsar actividades de prevención, diagnóstico precoz y tratamiento antes de llegar a la situación extrema del ingreso en los centros específicos de protección,

de la Ley foral 15/2005, del art. 49 de la Ley gallega 3/2011 y del art. 40 de la Ley 1/2006 de La Rioja. Excepcionalmente, incluye en la noción «situación de riesgo» los problemas conductuales del menor el art. 34.2.h de la Ley 5/2014 de Castilla-La Mancha que transcribo por su interés: «Se consideran factores de riesgo de un menor los siguientes: [...] h) La incapacidad o imposibilidad de controlar la conducta del menor y que pueda tener como resultado el daño a sí mismo o a terceras personas». Asimismo, conviene reparar en el amplio concepto que de tal situación ofrecen algunas leyes autonómicas, donde bien puede tener cabida la situación descrita; tal es el caso del art. 56 de la Ley aragonesa 12/2001, del art. 93 de la Ley valenciana 12/2008 y del art. 51 de la Ley vasca 3/2005, que se refieren a aquellas situaciones en que el desarrollo integral del menor se ve perjudicado por "circunstancias personales o socio-familiares».

23 Art. 40 de la Ley andaluza 1/1998, art. 79 de la Ley aragonesa 12/2001, art. 3.d de la Ley balear 17/2006, art. 49 de la Ley 5/2014 de Castilla-La Mancha, arts. 83.2 y 84.c de la Ley foral 15/2005, arts. 68.a y 69 de la Ley madrileña 6/1995 y art. 58 de la Ley valenciana $12 / 2008$.

24 Art. 27 de la Ley asturiana 1/1995, arts. 32, 34.3 y 4 y 53 de la Ley cántabra 8/2010, arts. 37.4 y 104.b de la Ley catalana 14/2010, art. 38.5.c de la Ley 14/2002 de Castilla y León, arts. 32 y 60 de la Ley gallega 3/2011, arts. 45 y 60 de la Ley 1/2006 de La Rioja, art. 87.a y c de la Ley valenciana 12/2008 y art. 48.c de la Ley vasca 3/2005.

Véase en el mismo sentido Palma del Teso (2006: 177). No obstante, salvo error u omisión, tras la consulta de las páginas web de los servicios de protección de infancia de las diferentes comunidades autónomas, solo puede darse noticia de la puesta en marcha por parte de la Junta de Andalucía de un programa específico de prevención dirigido al concreto colectivo menores que nos ocupa: los programas preventivos para la atención, orientación e intervención a familias con menores en situación de conflicto o dificultad social, dirigidos tanto a desarrollar competencias sociales en el menor como a promover la parentalidad positiva. 
el cual, sin embargo, sí que cuenta con un protocolo propio (el Protocolo básico de actuación en centros y/o residencias con menores diagnosticados con trastornos de conducta de 2010). En cualquier caso, considero que esta actuación protectora de índole preventiva difícilmente será factible cuando los progenitores no presten la necesaria colaboración ${ }^{26}$, ello sin perjuicio de que en tal caso puede declararse el desamparo del menor si así lo requiere la evolución de la situación de riesgo ${ }^{27}$. Es más, algunas normas autonómicas parecen supeditar tal intervención de la Entidad Pública a que sean los propios progenitores los que recaben su auxilio ${ }^{28}$.

\section{EL ACOGIMIENTO RESIDENCIAL DE MENORES CON PROBLEMAS DE CONDUCTA COMO ÚLTIMO INSTRUMENTO DE PROTECCIÓN}

\section{PRELIMINARES}

Como se ha apuntado ab initio, una de las principales novedades de la LO 8/2015 se tradujo en la incorporación a la LOPJM, como modalidad

26 En este sentido el art. 68 de la Ley madrileña 6/1995 y el art. 79.2 de la Ley aragonesa $12 / 2001$ prevén que las actuaciones administrativas con menores en conflicto social, tanto de carácter preventivo como de reinserción, «procurarán contar con la voluntad favorable del menor» y sus progenitores, tutores o guardadores (la cursiva es nuestra). Por su parte, el art. 84.2 y 3 de la Ley foral 15/2005 exige el compromiso voluntario de participación, tanto del menor como de su familia, pudiendo, en su defecto, la Administración de la Comunidad Foral de Navarra solicitar autorización judicial.

27 Véase en el mismo sentido Palma del Teso (2006: 181) y García Pérez (2018: 6). De hecho, tal afirmación puede sustentarse en la previsión contenida en la legislación autonómica de protección de menores, según la cual la falta de colaboración de los progenitores en la ejecución de las medidas de protección adoptadas podrá dar lugar a la declaración de desamparo según evolucione la situación de riesgo; véanse el art. 58 de la Ley aragonesa 12/2001, el art. 62.1.i de la Ley cántabra 8/2010, el art. 37.I de la Ley 5/2014 de Castilla-La Mancha, el art. 56.i de la Ley de Castilla y León, 14/2002, el art. 103.6 de la Ley catalana 14/2010, el art. 57 de la Ley gallega 3/2011, el art. 46.a de la Ley foral 15/2005, el art. 42.4 de la Ley 1/2006 de La Rioja y el art. 97 de la Ley valenciana $12 / 2008$.

28 En particular, el art. 49 de la Ley 5/2014 de Castilla-La Mancha y el art. 60 de la Ley 1/2006 La Rioja. Ahora bien, en atención a lo dispuesto en el art. 13.1 LOPJM, no cabe descartar que la acción protectora de la Administración se ponga en marcha previa denuncia de la situación de riesgo por parte de cualquier persona del entorno del menor. 
especial de acogimiento residencial, del acogimiento en centros específicos de protección de menores con problemas de conducta, dotándolo a la par de un régimen jurídico muy detallado (arts. 25 a 35). De modo complementario, introdujo un nuevo precepto en la Ley de Enjuiciamiento Civil, el art. 778 bis, que, inspirado en el art. 763 relativo al internamiento en centros por trastorno psíquico, supedita tal ingreso a la correspondiente autorización judicial, así como su ulterior control y cese.

Tal reforma era ineludible ante el tratamiento dispensado a este recurso de protección por la normativa autonómica de protección de menores, ya no solo muy heterogéneo y fragmentario, sino de dudosa constitucionalidad ${ }^{29}$. Fue, en concreto, a partir de la primera década del presente siglo cuando las comunidades autónomas configuraron paulatinamente a través de normas de rango muy diverso una modalidad especial de centros de protección reservados a los menores objeto de este estudio. Al margen de la oportunidad o no del recurso en sí mismo sobre lo que me pronunciaré en el subepígrafe siguiente, importa aquí subrayar, de una parte, la preocupante ausencia en las normas autonómicas de un criterio uniforme en la configuración tanto del perfil de los menores destinatarios de estos centros específicos como de la tipología de los $\operatorname{mismos}^{30} ; \mathrm{y}$, de otra, la discutible previsión por parte de no pocas de ellas

29 De acuerdo con la Fiscalía General del Estado (Memoria 2010: 976-977 y 2011: 32 y 34) y el Consejo Económico y Social (2014: 11-12). En la doctrina cuestionan esta normativa De Palma del Teso (2006: 172-176), Díez García (2010: 202-203 y 260261), Galán Rodríguez (2013: 25), Sainz-Cantero Caparrós (2014: 128), Ferreiros Marcos (2016: 64-68) y Vázquez Pastor-Jiménez (2016: 135-136).

30 Véase el art. 40 de la Ley andaluza 1/1998 y la Orden de 28 de julio de 2000 de las Consejerías de la Presidencia y de Asuntos Sociales de la Junta de Andalucía, por la que se regulan los requisitos materiales y funcionales de los servicios y centros de servicios sociales de Andalucía y se aprueba el modelo de solicitud de las autorizaciones administrativas (anexo I, apdo. 2.5.2), el art. 78 de la Ley aragonesa 12/2001, el art. 9.5 del Decreto 238/1994 por el que se regula la organización y funcionamiento de los centros de protección de menores de la Comunidad Autónoma de Aragón y la Orden de 14 de diciembre de 1994 del Departamento de Bienestar Social y Trabajo por la que se aprueba el proyecto educativo marco para los centros de protección de menores dependientes de la Comunidad Autónoma de Aragón (apdo. III.d), los arts. 9 a 13 del Decreto asturiano 48/2003 por el que aprueba el reglamento sobre normas de régimen interior de centros de alojamiento de menores, el art. 91.2.g de la Ley balear 17/2006, los arts. 46, 47, 69 y 82.1c de la Ley 5/2014 de Castilla-La Mancha, el art. 96.6 de la Ley 14/2002 de Castilla y León, el art. 133 de la Ley catalana 14/2010, los arts. 83 y 84.1.c de la Ley foral 15/2005, el art. 14 del Decreto gallego $329 / 2005$, de 28 de julio, por el que se regulan los centros de menores y los centros 
de medidas restrictivas de derechos fundamentales, cuando esta materia está reservada a la Ley Orgánica ex art. 81.1 $\mathrm{CE}^{31}$. Junto a ello conviene reparar en el muy incompleto desarrollo normativo de que fue objeto este recurso de protección por parte de los legisladores autonómicos, llegándose a relegar en algunas comunidades autónomas la fijación del régimen de estos centros a normas de rango reglamentario e, incluso, a instrumentos no normativos, lo que no puede dejar de cuestionarse, asimismo, desde una perspectiva constitucional $^{32}$.

Es más, las irregularidades detectadas en el funcionamiento de algunos de estos centros fueron denunciadas por el Defensor del Pueblo en su informe sobre «Centros de protección de menores con trastornos de conducta y dificultad social» de $2009^{33}$. Sus conclusiones y recomendaciones, tanto por lo que hace a los propios centros y su personal como al procedimiento a seguir para acordar el oportuno ingreso, tuvieron un fuerte impacto mediático y dieron lugar a diferentes iniciativas dirigidas a organizar el funcionamiento de los mismos ${ }^{34}$.

Entre dichas iniciativas interesa destacar el Protocolo básico de actuación en centros y/o residencias con menores diagnosticados con trastornos de conducta que en 2010 elaboró la Comisión Interautonómica de Directores

de atención a la infancia, el art. 91.3 de la Ley 1/2006 de La Rioja, el art. 67 de la Ley madrileña 6/1995 y el art. 3.f del Decreto 88/1998, por el que se aprueba el estatuto de las residencias de atención a la infancia y adolescencia, los arts. 57, 59 y 112.3 de la Ley valenciana 12/2008, el art. 78.2 de la Ley vasca 3/2005 y los arts. 2.3.b, 4.2.2.a y b, 5.3 y 6.1.a del Decreto vasco 131/2008. Una completa reseña de esta normativa puede consultarse en Ferreirós Marcos (2016: 69-78).

31 Como, igualmente, advierte Díez García (2010: 259-271 y 283-285), ofreciendo un riguroso examen de este extremo. En particular, contemplan la posibilidad de adoptar medidas restrictivas el art. 133.2 de la Ley catalana 14/2010, los arts. 95 y 96 de la Ley foral 15/2005, el art. 112.3 de la Ley valenciana 12/2008 e incluso normas con rango reglamentario como el art. 6.i del Decreto 37/2004 de Castilla y León por el que se regulan los requisitos mínimos y específicos de autorización para la apertura y funcionamiento de los centros destinados a la atención de menores con medidas o actuaciones de protección y los arts. 99 a 101 del Decreto vasco 131/2008.

32 Tal es el caso de la Comunidad Autónoma de Canarias, donde este recurso de protección se contempla en el I Plan Integral de Protección del Menor en Canarias actualmente en fase de renovación- y en el Plan Insular de Atención al Menor y la Familia de Tenerife (2007-2009) elaborado por el Instituto Insular de Atención Social y Socio-sanitaria del Cabildo, instrumentos ambos sin carácter normativo.

33 Véanse sus conclusiones en pp. 389-402 y recomendaciones en pp. 403-416.

34 De acuerdo con Galán Rodríguez (2013: 24) y Vázquez Pastor-Jiménez (2017: 136). 
Generales de Infancia, haciéndose eco de una de las recomendaciones del Defensor del Pueblo (I.2) ${ }^{35}$. Ahora bien, aun constituyendo un esfuerzo muy necesario y positivo, no resultó del todo satisfactorio por dos razones fundamentalmente: su carencia de rango normativo y la insuficiencia de las garantías allí previstas ${ }^{36}$.

Otra institución muy sensible a la confusión generada por la difusa normativa autonómica fue la Fiscalía General del Estado, habida cuenta que el Ministerio Fiscal tiene encomendada la superior vigilancia de la intervención protectora de la Administración (art. 174 CC). Así, en su Circular 8/2011 reivindicó la supervisión de los ingresos en estos centros por parte del Ministerio Fiscal, así como la necesaria intervención judicial (Fiscalía General del Estado, 2011: 56).

Se imponía así, como recomendó el Comité de los Derechos del Niño de Naciones Unidas en 2010 y, a nivel nacional, el Defensor del Pueblo en su Informe de 2009 y la Fiscalía General del Estado en su Memoria de 2010 ${ }^{37}$, un tratamiento jurídico completo y homogéneo que unificase, con rango de ley orgánica y ámbito estatal, la definición y el régimen de estos centros, desde la perspectiva de los derechos y la seguridad jurídica de los menores y sus familias y de los profesionales implicados.

Este desideratum fructificó en la creación durante la IX Legislatura en el seno del Senado de una Comisión especial de estudio de la problemática de la adopción internacional y otros temas afines donde se abordó la necesidad de una reforma en profundidad del sistema de protección a la infancia y adolescencia, con especial atención al concreto instrumento de protección que nos ocupa ${ }^{38}$. La reforma definitiva, articulada en torno a dos leyes, no sería aprobada hasta la legislatura siguiente, tras un largo ínterin de trabajos

35 Defensor del Pueblo (2009: 404). Asimismo, esta fue una de las recomendaciones del Comité de los Derechos del Niño de Naciones Unidas dirigidas a España en 2010 (recomendación 42).

36 Según se hizo constar en las comparecencias a la Comisión especial del Senado (actas de las sesiones de 7 de marzo de 2011: 3 y de 4 de abril de 2011: 16-17).

37 Comité de los Derechos del Niño de Naciones Unidas (2010: recomendación 41), Defensor del Pueblo (2009: 404-405) y Fiscalía General del Estado (Memoria 2010: 977). Véase en el mismo sentido Amnistía Internacional en su comparecencia en la Comisión especial del Senado (acta de la sesión de 7 de marzo de 2011: 4).

38 Nótese que la Comisión dedicó específicamente sus sesiones de 7 de marzo a 20 de septiembre de 2011 a abordar la problemática de estos centros, cuyas conclusiones se materializaron en una serie de propuestas legislativas contenidas en su informe de 21 de septiembre de 2011, buena parte de las cuales fueron acogidas en el texto definitivamente aprobado. 
preliminares que se materializaron primero en el anteproyecto de ley de actualización de la legislación sobre protección a la infancia de 2011 y ulteriormente en los anteproyectos de ley de protección de la infancia y de ley orgánica complementaria de la Ley de Protección de la Infancia de 2014. Estos últimos constituyen el antecedente inmediato de los proyectos de ley orgánica y de ley de modificación del sistema de protección a la infancia de 2015, los cuales fueron aprobados, tras la correspondiente tramitación parlamentaria, como LO 8/2015 y Ley 26/2015.

\section{TIPOLOGÍA Y SUBSIGUIENTE OPORTUNIDAD}

Difícilmente puede abordarse el análisis de este recurso reservado a los menores con problemas de conducta sin plantearnos a priori la oportunidad del mismo, en atención a sus importantes singularidades que lo convierten en una suerte de tertium genus entre los centros ordinarios de protección y los centros de reforma. En efecto, son centros que revisten singularidades, porque autorizan la aplicación de medidas restrictivas de derechos fundamentales y tienen un reglamento de régimen interno más estricto que los centros de protección ordinarios que incluye medidas disciplinarias. Pero, ante todo, son centros vinculados al ámbito de protección de menores, si bien reservados excepcional y exclusivamente a menores con graves problemas de inadaptación familiar y social "cuando las instancias familiares y educativas ordinarias no existen o han fracasado [...] en la necesidad de proporcionar a estos menores un contexto más estructurado socio-educativo y psicoterapéutico que solo un programa específico pueda ofrecerle», según puede leerse en el preámbulo de la LO 8/2015 (apdo. II.11) ${ }^{39}$. En este sentido, es de valorar muy positivamente el esfuerzo desplegado por el legislador estatal a la hora de abordar su régimen jurídico, con la doble finalidad, por un lado, de eliminar toda conexión con los antiguos correccionales reservados a los denominados «menores peligrosos $»^{40}$, como así resulta de la siguiente declaración vertida también en el preámbulo de la LO 8/2015 (apdo. II.11) según la cual estos centros no pueden concebirse como «instrumentos de defensa social frente a menores conflictivos» ${ }^{41}$; $y$, por otro, de dotar al ingreso en los mismos de

39 La misma precisión se recoge en las comparecencias a la Comisión especial del Senado (acta de la sesión de 28 de marzo de 2011: 26).

40 Sobre la evolución normativa en el tratamiento de este colectivo de menores puede consultarse Palma del Teso (2006: 17-36) y Ferreirós Marcos (2016: 3-15).

41 Idea también presente en las comparecencias en la Comisión especial del Senado (actas de las sesiones de 28 de marzo de 2011: 26 y de 13 de junio de 2011: 5). 
importantes garantías de conformidad con los postulados constitucionales y las recomendaciones vertidas sobre el particular por diversas instancias internacionales. Concebida así esta medida en derecho español tras la reforma de 2015 como de índole exclusivamente protectora-educativa y no reformadora, en principio creo que puede defenderse su virtualidad como último recurso de protección ante situaciones de grave dificultad social, dirigido exclusivamente a normalizar la conducta de los menores y a garantizar el pleno desarrollo de su personalidad ${ }^{42}$; ello sin perjuicio de ciertas omisiones y deficiencias detectadas en su régimen jurídico, tal y como ha sido configurado por el legislador estatal en 2015.

\section{PRINCIPIOS RECTORES}

En estrecha conexión con lo anterior interesa reparar en los principios rectores de este recurso de protección, tal y como han sido articulados por la reforma de 2015 de modo acorde con las recomendaciones vertidas tanto por Naciones Unidas como por el Consejo de Europa ${ }^{43}$.

El primero de ellos es el subsidiariedad ${ }^{44}$, en el sentido de que «el acogimiento residencial en estos centros se realizará exclusivamente cuando no sea posible la intervención a través de otras medidas de protección» (art. 25.2 LOPJM) o, en otras palabras, cuando no existan medidas menos restrictivas que produzcan los mismos efectos (art. 778 bis. 4 in fine LEC). Obviamente, ello se justifica por la afección a los derechos fundamentales de los menores inherente a su ingreso, pero también por la necesaria especialización del tratamiento a que se refiere el art. 25. 2 LOPJM.

El segundo es el de proporcionalidad ${ }^{45}$, lo que implica la permanencia de los menores en estos centros durante el tiempo estrictamente necesario para atender a sus necesidades específicas (arts. 26.5 LOPJM y 778 bis.7.1 LEC).

42 Comparto así la opinión Palma del Teso (2006: 168-169 y 175). Justifican, asimismo, la existencia de ese recurso de protección el Consejo Fiscal (2014: 11) y Gómez Aparicio (2013: 279). Lo cuestionan, sin embargo, Díez García (2010: 277 y 279-280) y Ferreirós Marcos (2017: 24), sin duda ante el temor de un posible retorno a la noción de «infancia peligrosa».

43 Asamblea General de las Naciones Unidas (1990: reglas 1, 2, 31-37, 81, 82 y 87), Comité de los Derechos del Niño de Naciones Unidas (2010: recomendación 42.a y d) y Comité de Ministros del Consejo de Europa (2005: apdo. I, reglas 2 y 3 y aptdo. III).

44 Principio enunciado por la Fiscalía General del Estado (2016: 12 y 17).

45 Principio enunciado por la Fiscalía General del Estado (Memoria 2010: 977) y el Consejo Económico y Social (2014: 14). 
La adopción de las medidas restrictivas de derechos fundamentales ha de responder, igualmente, a dicho principio (arts. 27.1 y 34.1.2 LOPJM).

El tercero es el de especialización ${ }^{46}$, en cuanto que la utilización de este recurso de protección debe estar justificada por las necesidades específicas de protección del menor (art. 25.2 LOPJM). En efecto, los menores con problemas de conducta, cuando precisan de una medida de protección con ingreso en un centro específico, tienen unas necesidades muy concretas que, a su vez, requieren la debida especialización de los centros de protección - ya sean de titularidad pública o dependientes de entidades privadas colaboradoras $-{ }^{47}$, tal y como se deriva del propio articulado de la LOPJM tras la reforma de 2015. Así, la lectura conjunta de los apdos. 1.2, 2 y 4 de su art. 25 muestra la preocupación del legislador estatal — no acompañada, sin embargo, de unos recursos económicos adicionales: DF 5a LO 8/2015— ${ }^{48}$ por dotar a este recurso de unos centros que permitan prestar a los menores con problemas de conducta de una atención especial en un contexto estructurado y con programas específicos que se adecúen a los estándares internacionales y criterios de calidad $^{49}$ y que, por añadidura, dispongan de una ratio adecuada entre el número de menores y el personal — necesariamente especializado- destinado a su atención para garantizarles un tratamiento personalizado.

$\mathrm{Y}$ en cuarto lugar, pero indudablemente en primer orden de importancia, conviene reparar en el principio del interés superior del menor, que, en todo caso, debe inspirar la intervención de la Administración en materia de protección de menores y, en particular, sus decisiones sobre el acogimiento residencial, según resulta de los arts. 11.2 y 21.1.c LOPJM, puestos en relación

46 Principio enunciado por la Fiscalía General del Estado (2016: 13).

47 De acuerdo con el Consejo Fiscal (2014: 11). A este respecto García Díez (2016: $17-$ 20) recuerda el papel reservado al Ministerio Fiscal de garante del cumplimiento de la normativa aplicable.

48 Discrepo así con el Consejo de Estado (2014: 37) de la justificación que ofreció el Ministerio de Sanidad, Servicios Sociales e Igualdad (2015: 18-19) sobre el nulo impacto económico y, por ende, presupuestario de la LO 8/2015. Y es que, como advirtió en su momento el Defensor del Pueblo (2009: 404), «se deben evitar la habilitación de nuevos recursos que no reúnan las condiciones idóneas para el desarrollo de cualquier proyecto que conlleve el acogimiento residencial de menores». La misma reflexión hace Martín Azcano (2015: 4).

49 A este respecto interesa reparar en las Reglas de las Naciones Unidas para la protección de los menores privados de libertad (reglas 31-37 y 81-82) y los Estándares de calidad en acogimiento residencial (EQUAR) publicados por el Ministerio de Sanidad, Servicios Sociales e Igualdad en 2012. 
con el art. 2.1 del mismo texto legal ${ }^{50}$. Con todo, hubiera sido deseable que en los preceptos que la LOPJM dedica específicamente a esta modalidad de acogimiento residencial se hubiera insistido en la relevancia de este principio más allá de dos meras referencias en sede de restricciones en el régimen de visitas y de comunicaciones y de salidas (arts. 34.2 y 35.2), habida cuenta de sus especificidades ${ }^{51}$.

\section{DESTINATARIOS}

\subsection{La noción legal y sus problemas interpretativos}

La correcta aplicación de un recurso de protección tan singular como el que nos ocupa pasa por la necesaria delimitación del colectivo de menores al que está reservado, habida cuenta de su importante incidencia en el ámbito de los derechos fundamentales. Resulta innegable que el legislador estatal ha hecho un importante esfuerzo en este sentido, tratando así de poner fin al confuso panorama generado por la legislación autonómica ${ }^{52}$. Pero, aun con todo, son numerosos los interrogantes que, a mi entender, plantea la noción que de este colectivo ofrece la LOPJM tras la reforma de 2015, como se verá a continuación. A priori, de la lectura conjunta de sus arts. 25 y 26 resulta que dos son los presupuestos a cumplir por los menores para ser objeto de ingreso en un centro de protección específico: primero, han de encontrarse bajo la guarda o tutela de la Administración; y segundo, deben haber sido diagnosticados con problemas de conducta.

a) Menores bajo tutela o guarda administrativa

El primer presupuesto delimitador del ámbito subjetivo de esta modalidad de acogimiento residencial radica en la necesaria situación de tutela o guarda administrativa en que deben encontrarse los menores, en atención a la previsión contenida en el art. 25.1.2 LOPJM, según la cual estos centros de protección específicos «estarán destinados al acogimiento residencial de menores que estén en situación de guarda o tutela de la Entidad Pública» ${ }^{53}$.

50 Como ya advirtió en su momento Gómez Aparicio (2013: 280).

51 Como advirtió, en fase de anteproyecto de 2014, el Consejo General del Poder Judicial (2014: 26).

52 Sobre este particular, véase más ampliamente Diez García (2010: 227-240).

53 Este precepto se complementa con la declaración contenida en el preámbulo de la LO $8 / 2015$ relativa a que «estos centros de protección a la infancia tienen en cuenta las 
Así, son destinatarios de esta medida de protección exclusivamente aquellos menores que se encuentren bajo la guarda de la correspondiente Entidad Pública, lo que a priori no deja de tener su lógica, desde el momento en que dicha medida se configura como una modalidad de acogimiento residencial, a través del cual «se realiza» la guarda asumida por la Administración (art. 172 ter. 1 CC) $)^{54}$. Pero, no se olvide, ello supone que los menores a los que se reserva este recurso se encuentran en una situación extrema que ha motivado la intervención de la Administración, con la consiguiente suspensión de los deberes de guarda de los progenitores e, incluso, de la patria potestad $-\mathrm{O}$, en su caso, de la autoridad familiar o responsabilidad parental - de haber sido declarados en desamparo. A partir de ahí, la asunción de su guarda por la Entidad Pública de protección de menores competente puede obedecer a dos motivos distintos: bien porque la Administración haya declarado su desamparo con la consiguiente atribución de la tutela automática o ex lege (art. 172 $\mathrm{CC}$ ); bien a solicitud de los progenitores $-\mathrm{o}$, en su caso, tutor ordinario- $\mathrm{o}$ por resolución judicial, en cuyo caso el menor quedará en situación de guarda administrativa (art. 172 bis CC).

Ciertamente, en la mayor parte de las ocasiones serán los propios progenitores — $\mathrm{o}$, en su caso, el tutor ordinario — los que recaben el auxilio de la Administración, alegando para ello no poder prestar a sus hijos la asistencia debida como consecuencia de la grave inadaptación de estos a su entorno familiar y social, lo que determinará la asunción temporal de la guarda por la

especiales características, complejidad, condiciones y necesidades de estos menores, que requieren de una intervención especializada, cuando se encuentren bajo la protección de la Entidad Pública» (la cursiva es nuestra). Por añadidura, el art. 778 bis LEC no reconoce legitimación a los progenitores para solicitar la autorización judicial de ingreso de los menores en estos centros.

En particular, el acogimiento residencial — subsidiario, en todo caso, del acogimiento familiar, ex art. 21.3 LOPJM y art. 172 ter CC - consiste en ingresar al menor en un centro de protección adecuado a sus características para que reciba la atención y educación necesarias, tal y como se define en la legislación autonómica de protección de menores; véanse por ejemplo el art. 27.a. de la Ley andaluza 1/1998, el art. 162.2 CDFA y los arts. 64.2 y 66.1 de la Ley aragonesa 12/2001, el art. 87.1 de la Ley balear 17/2006, el art. 120.2 de la Ley catalana 14/2010, el art. 69.b. de la Ley foral 15/2005, el art. 27.b. de la Ley gallega 3/2011, el art. 63.3 de la Ley 1/2006 de La Rioja, el art. 115.2 de la Ley valenciana 12/2008 y el art. 80 de la Ley vasca 3/2005. En tal caso, el ejercicio de la guarda se delega en el director o responsable del centro donde esté acogido el menor, quien habrá de ejercerla con la colaboración y supervisión de la Entidad Pública y bajo la vigilancia del Ministerio Fiscal (art. 172 ter.1 in fine CC, en relación con los arts. 21.4 LOPJM y 174 CC). 
Entidad Pública, en principio, por un plazo máximo de dos años, siempre que se acredite que tal conducta adolece de suficiente gravedad y, por añadidura, puede reconducirse en un tiempo limitado, de conformidad con lo dispuesto en el art. 172 bis. 1 CC $^{55}$. En idénticas circunstancias - graves, transitorias y ajenas a la voluntad de los progenitores - también podrá constituirse la guarda administrativa si así lo decide el juez, a solicitud de la propia Entidad Pública cuando considere excesiva una intervención de tal calado como es la declaración de desamparo ${ }^{56}$, del Ministerio Fiscal (art. 174.2.1, en relación con el art. 158.6 $\left.6^{\circ} \mathrm{CC}\right)^{57} \mathrm{o}$, incluso, de los propios progenitores en el caso de que la Entidad Pública se niegue a asumirla voluntariamente, formulando para ello la oportuna oposición ante la jurisdicción civil ex art. 780.2 LEC ${ }^{58}$.

55 Como advierte Gómez Aparicio (2013: 281). De hecho, la Ley 5/2014 de Castilla-La Mancha limita a este supuesto su intervención respecto de los «menores con conducta inadaptada». Así, su art. 69 dispone que, en caso de que resulte imposible la permanencia del menor en su propio entorno, se propondrá a los progenitores, tutores o guardadores que soliciten la cesión de la guarda para su asunción por la Entidad Pública.

56 Puede invocarse a este respecto el art. 79.3 de la Ley aragonesa 12/2001. Ahora bien, como advierte Díez García (2010: 255), sorprende que la Administración no pueda autoatribuirse la mera guarda, cuando, sin embargo, se le permite asumir la tutela, constituyendo esta — añado yo- una intervención mucho más enérgica en el ámbito de la protección de menores.

57 Recuérdese que el art. 174.2.2 CC faculta al Ministerio Fiscal para promover ante la Entidad Pública o el juez las medidas de protección que estime necesarias. Complementariamente, el art. 158.6 $\mathrm{CC}$ incluye al Ministerio Fiscal entre los legitimados para solicitar al juez las «disposiciones que considere oportunas, a fin de apartar a un menor de un peligro o de evitarle perjuicios en su entorno familiar». A partir de ahí, no son pocos los autores que defienden la posibilidad de acordar judicialmente la guarda administrativa al amparo de dichos preceptos, tesis que personalmente suscribo; entre otros, Llebaría Samper (1990: 90), Mayor del Hoyo (1999: 307) y, en fechas más recientes, Díez García (2010: 255).

El tenor del art. 172 bis CC y, sobre todo, las previsiones autonómicas en materia de guarda administrativa (art. 24.1 de la Ley andaluza 1/1998, art. 64 de la Ley aragonesa 12/2001, art. 40.1 de la Ley asturiana, art. 69 de la Ley cántabra 8/2010, art. 43 de la Ley 5/2014 de Castilla-La Mancha, art. 87 de la Ley 14/2002 de Castilla y León, art. 59 de la Ley foral 15/2005, art. 62 de la Ley 1/2006 de La Rioja, art. 105.1 de la Ley 12/2008 valenciana y art. 64.2 de la Ley vasca 3/2005) permiten entender que la Administración no podrá negarse a asumir la guarda cuando se acrediten debidamente las circunstancias a que se refiere el art. 172 bis.1 CC. Ahora bien, como afirma Mayor del Hoyo (1999: 263) y corroboran los arts. 11.2 y 12.2 de la Ley 2/2006 de Derecho Civil de Galicia, no cabe descartar que la Administración deniegue la 
Pero tampoco hay que descartar que los comportamientos gravemente trasgresores en que incurren los menores tengan como causa coadyuvante la ausencia o inadecuado ejercicio de los deberes inherentes a la patria potestad por parte de sus progenitores - entre los que se incluye, no se olvide, el deber de procurar a los hijos una formación integral ex art. $154.3 .1^{\circ} \mathrm{CC}-59 \mathrm{con}$ la consiguiente privación absoluta de asistencia a aquellos, en cuyo caso ya no procederá la mera guarda administrativa, sino la declaración de desamparo y subsiguiente asunción de la tutela ex lege por la Entidad Pública ${ }^{60}$. Es más, cuando ello suceda, los problemas de conducta de que adolecen estos menores se verán agudizados en función de la concreta causa que haya provocado la grave situación de inasistencia ya no solo material, sino moral, en que se encuentran (March, 2007:216); piénsese en situaciones tales como la inhibición absoluta de los progenitores del cumplimiento de sus deberes de guarda, la violencia intrafamiliar o el consumo abusivo por el menor de sustancias adictivas tales como drogas o alcohol con la tolerancia de sus progenitores, circunstancias todas ellas constitutivas de desamparo cuando se den con la suficiente gravedad, conforme al art. 18.2.4 LOPJM. Ello sin olvidar aquellos casos en que, una vez transcurrido el plazo de la guarda administrativa, sus progenitores no quieran o estén imposibilitados para asumirla, lo que conllevará, igualmente, la declaración de desamparo (art. 18.2.4.b LOPJM).

En los términos en que se expresa la legislación estatal vigente, queda claro, por tanto, que el recurso de protección que nos ocupa se encuentra reservado a aquellos casos en que los progenitores hayan sido excluidos de la guarda de sus hijos, ya sea por su propia voluntad o no, en favor de la Entidad

solicitud, bien sin motivación alguna o por apreciar que no concurre el supuesto de hecho contemplado por el precitado precepto del CC, en cuyo caso, a mi juicio, los progenitores podrán formular oposición ante la jurisdicción civil, con base en lo dispuesto en el art. 780 LEC. En la misma línea, la Fiscalía General del Estado (Memoria 2010: 971-972) no descarta que sea el fiscal el que proponga la guarda judicialmente con base en el art. 158 CC «ante la denegación de la guarda voluntaria o el silencio de la Entidad Pública».

59 Deber que también recalca García Pérez (2018: 11).

60 Discrepo en este punto de Díez García (2010: 250-257), quien cuestiona la oportunidad de la declaración de desamparo de los menores con problemas de conducta, por considerar situaciones distintas la propia conducta disruptiva del menor y la inasistencia generada por la conducta dolosa o negligente de sus progenitores a que se refiere el art. 172 CC. No obstante, más adelante la misma autora no descarta que la causa del comportamiento del menor se encuentre en un inadecuado ejercicio de las funciones parentales. 
Pública, habiendo asumido esta ya sea la tutela o la guarda administrativa ${ }^{61}$. Esta opción legislativa deja, sin embargo, sin resolver la espinosa cuestión referente al posible ingreso de un menor en un centro privado de formación especial por decisión de sus progenitores cuando siga bajo su guarda ${ }^{62}$. Se ha prescindido así de incorporar al texto definitivo de la LO 8/2015 el art. 763 bis LEC redactado por los autores del anteproyecto de 2014, donde, a mi entender, se dirimía esta cuestión de modo acertado, en cuanto se dejaba abierta la posibilidad de que fuesen los propios progenitores los que decidiesen recurrir una medida de estas características como último recurso, si bien se supeditaba a autorización judicial y a las mismas garantías previstas para el ingreso de los menores bajo la protección de la Entidad Pública ${ }^{63}$. Así, su apdo. 1 , tras reconocer en su primera parte — de modo coincidente con la redacción actual del art. 778 bis.1 LEC — la legitimación a la Entidad Pública tutora o guardadora y al Ministerio Fiscal para solicitar la autorización judicial para el ingreso del menor en los centros de protección específicos, atribuía idéntica legitimación a los progenitores o tutor que ostentasen la patria potestad o tutela ordinaria para solicitar su ingreso en los «centros privados para menores con medidas de restricción de derechos fundamentales que no estuviesen bajo una medida de protección de la Entidad Pública». De modo complementario a esta previsión, el anteproyecto contenía una disposición adicional en la que declaraba aplicable a tales centros el régimen jurídico de los arts. 25 y ss. LOPJM, con el objeto de dotar de idénticas garantías al ingreso de los menores en todo centro que pueda incidir en sus derechos fundamentales.

Suprimidos ambos preceptos en el proyecto de ley, y en ausencia de previsión específica al respecto, solo queda el art. 154.4 CC, que permite a los progenitores recabar el auxilio de la autoridad en el ejercicio de la patria potestad $^{64}$. De este modo, no cabe descartar que, al amparo de este precepto, los

61 Véase en el mismo sentido la Comisión especial del Senado (acta de la sesión de 28 de marzo de 2011: 27) y la Fiscalía General del Estado (2016: 21). Esta situación fue cuestionada antes de la reforma 2015 por el Defensor del Pueblo (2009: 67-68 y 406), así como, en fase de trabajos preparatorios, en las comparecencias a la Comisión especial del Senado (acta de la sesión de 4 de abril de 2011: 27).

62 Obviamente, el ingreso en los centros de titularidad pública está restringido a los menores que se encuentren bajo una medida de protección de la Entidad Pública (fuente: técnicos del IASS). Me permito así discrepar de las objeciones formuladas al respecto, en fase del anteproyecto de 2014, por el Consejo General del Poder Judicial (2014: 32-33) y el Consejo Fiscal (2014: 19).

64 Como advierte, asimismo, García Pérez (2018: 4, 9 y 11). Por su parte, Martín Azcano (2015: 6), defiende la aplicación analógica a los progenitores del art. 271.1º 
progenitores soliciten en casos extremos al juez el ingreso de sus hijos menores en un centro de formación especial cuando concurran las circunstancias a que se refiere el art. 25.1 LOPJM ${ }^{65}$; solicitud esta que, a mi juicio, solo deberá ser atendida por el juez si se acredita debidamente la necesidad de acudir a este recurso, a fin de evitar actuaciones arbitrarias y contraventoras de los derechos de los menores ${ }^{66}$. Por añadidura, si el centro contempla la posible restricción de los derechos fundamentales, considero que, por razones de seguridad jurídica, habrían de aplicarse analógicamente las garantías y el régimen de supervisión de los arts. 25 y ss. LOPJM y 778 bis LEC $^{67}$.

\section{b) Menores diagnosticados con problemas de conducta}

El segundo presupuesto delimitador del recurso de protección que nos ocupa tiene que ver con la concreta tipología de los menores a los que está reservado, habida cuenta de las importantes singularidades que lo separan del ingreso en los centros de protección ordinarios. Esta era, sin duda, una de las principales dificultades a que tuvo que enfrentarse el legislador estatal cuando abordó su regulación ante la falta de consenso existente sobre el particular, como se desprende de la heterogénea normativa autonómica $y$, en fase preparatoria de la reforma de la LOPJM, de la ausencia de un criterio uniforme en las comparecencias de diversos especialistas en el ámbito

CC, precepto que supedita a autorización judicial el internamiento del tutelado en un centro de salud mental o educación especial. Esta solución personalmente no me convence, ya que difícilmente puede acudirse en este caso al recurso de la analogía, en ausencia de uno de sus presupuestos ex art. 4.1 CC como es la ausencia de norma, desde el momento en que los progenitores tienen reservado específicamente el art. 154.4 CC.

65 Veasé. en el mismo sentido García Pérez (2018: 5).

66 Este silencio del derecho estatal difiere, no obstante, de algunos derechos civiles territoriales, en particular, del derecho civil aragonés, cuyo Código Foral contiene una previsión específica sobre el particular: el art. 20, según el cual para internar a un menor contra su voluntad en un establecimiento, ya sea de salud mental o de educación o formación especial que comporte privación de libertad, se necesitará la correspondiente autorización judicial. Tema aparte es que pueda cuestionarse la constitucionalidad de este precepto, en cuanto regula una materia reservada a ley orgánica como es la restricción de la libertad personal; ello con base en la doctrina sentada por la STC 132/2010, de 2 diciembre, para declarar la inconstitucionalidad del art. 763.1 LEC.

67 Coincido así con Martín Azcano (2015. 6-7) y García Pérez (2018: 7). 
de la protección de menores en la Comisión especial del Senado $(2011)^{68}$. La cuestión fue resuelta no solo incluyendo en el art. 25.1.2 LOPJM una noción legal de tal colectivo que finalmente fue identificado con la expresión «menores con problemas de conducta» — delimitación positiva-, sino complementariamente mediante la exclusión del mismo de los menores que adolecen de un trastorno psíquico y de los menores infractores - delimitación negativa- Esta doble delimitación merece una valoración muy positiva $^{69}$, aunque no dejen de quedar, si se me permite la expresión, algunos flecos sueltos con los consiguientes problemas que ello conlleva en orden a la elección de la concreta medida a aplicar.

Como se ha indicado, en orden a su delimitación positiva debe acudirse al art. 25.1.2 LOPJM, precepto que atribuye la condición de menores con problemas de conducta a aquellos que, debidamente diagnosticados, "presentan conductas disruptivas o disociales recurrentes, transgresoras de las normas sociales y los derechos de terceros». Esta noción legal se ve complementada con el preámbulo de la LO 8/2015 cuando se refiere a la necesidad de articular instrumentos de protección específicos ante «situaciones muy conflictivas derivadas de problemas de comportamiento agresivo, inadaptación familiar, situaciones de violencia filioparental y graves dificultades para ejercer la responsabilidad parental» (apdo. II.9). De este modo, el legislador ha optado por una definición, procedente del Protocolo básico $(2010)^{70}$, que viene a recoger lo que podría calificarse de núcleo básico del denominado "trastorno de conducta»: la existencia de una grave y persistente situación de inadaptación familiar y social que se materializa en comportamientos disruptivos y aun agresivos ${ }^{71}$. No se hace mención alguna, sin embargo, a la gravedad del comportamiento, como, a mi entender, hubiera sido igualmente necesario ${ }^{72}$. Y es que conviene tener presente que el uso de este recurso de protección no se justifica por la presencia de meros

68 En dichas comparecencias se aprecia particularmente la difícil disociación entre los comportamientos disruptivos aprendidos y aquellos otros asociados a una patología psíquica (véanse, por ejemplo, las actas de las sesiones de 7 de marzo de 2011: 13 y 21, de 28 de marzo de 2011: 26-27, de 4 de abril de 2011: 4, 15-16 y 19, de 13 de junio de 2011: 14 y de 20 de junio de 2011: 3, 13 y 21).

69 Véase en el mismo sentido el Consejo Fiscal (2014: 13-14).

70 Comisión Interautonómica de Directores Generales de la Infancia (2010: 3).

71 De acuerdo con el DSM-V (la 5a y última ed. del Manual diagnóstico y estadístico de los trastornos mentales) de la American Psychiatric Association (2013: 469-470), así con la CIE 10 (Décima revisión de la clasificación internacional de las enfermedades) de la Organización Mundial de la Salud (1992: 325-326).

72 Sí, en cambio, en el preámbulo de la LO 8/2015, apdo. II.11. 
desajustes conductuales en los menores, sino que resulta determinante que se manifiesten en un grado tal que supongan un riesgo evidente de daños o perjuicios graves a sí mismos — autolesiones- y/o a terceros, como, de hecho, así se especifica en el Protocolo básico $(2010)^{73}$. Es más, dada la amplitud y, por ende, vaguedad de la noción legal, quizá hubiera resultado procedente articular a título ejemplificativo un elenco de posibles comportamientos que merezcan este calificativo, de modo paralelo a las concretas circunstancias constitutivas del desamparo a las que se ha dado entrada en el art. 18.2.4 LOPJM.

Un comentario aparte merece la expresión «menores con problemas de conducta» por la que se optó en el texto legal definitivamente aprobado para denominar a los destinatarios de este instrumento de protección, sustituyendo así tal expresión a la de «trastorno de conducta» presente en el anteproyecto de ley orgánica complementaria de la Ley de Protección de la Infancia de 2014 (art. 25). Comparto así la decisión del legislador de prescindir del término «trastorno de conducta» por sus connotaciones con los trastornos vinculados a problemas mentales, que no conductuales ${ }^{74}$; ello aparte de que su significado está todavía muy lejos de estar consensuado en la comunidad científica, como señalaron el Defensor del Pueblo en su informe de 2009 y el Consejo Económico y Social en su Dictamen de $2014^{75}$. No creo, sin embargo, que el término finalmente adoptado de «problema de conducta» resulte del todo

73 Comisión Interautonómica de Directores Generales de la Infancia (2010: 3). En la normativa autonómica de protección de menores incluyen tal nota caracterizadora el art. 40.1 de la Ley andaluza 1/1998, el art. 78.1 de la Ley aragonesa 12/2001, el art. 46 de la Ley 5/2014 de Castilla-La Mancha, el art. 96.7 de la Ley 14/2002 de Castilla y León, el art. 83.1 de la Ley foral 15/2005, el art. 67 de la Ley madrileña 6/1995, el art. 57 de la Ley valenciana 12/2008, el art. 78.2 de la Ley vasca 3/2005, el art. 9.1 del Decreto asturiano 48/2003 y el art. 6.1 del Decreto 37/2004 de Castilla y León.

74 Como señala la Fiscalía General del Estado (2016:8), «el enfoque de lo que puede definirse como problemas de conducta no debe realizarse exclusivamente desde una perspectiva de enfermedad» (la cursiva es nuestra). Cuestiona, asimismo, la expresión «trastorno de conducta» García Díez (2016: 5).

75 Defensor del Pueblo (2009: 29-31) y Consejo Económico y Social (2014: 13). Ello sin olvidar que el DSM-V (2013: 461-480) incluye los «trastornos de conducta» en la categoría más amplia de «trastornos disruptivos, del control de los impulsos y de la conducta» que aglutina hasta seis modalidades de trastorno mental cuyos contornos son muy difusos: el «trastorno negativista desafiante», el «trastorno explosivo intermitente», el «trastorno de conducta», el «trastorno de la personalidad antisocial», el «otro trastorno disruptivo, del control de los impulsos y de la conducta especificado» y el «trastorno disruptivo, del control de los impulsos y de la conducta no especificado». 
acertado $^{76}$, ya que, a mi juicio, no refleja claramente la gravedad de las circunstancias que justifican la adopción de una medida de protección tan singular, por lo que quizá hubiera sido más oportuno hablar de «menores con graves problemas de conducta» $\mathrm{o}$, en su caso, adoptar una denominación distinta, tal como la de «menores en dificultad social» acuñada por el Defensor del Pueblo en su Informe de $2009^{77}$.

La delimitación negativa viene dada por la exclusión del ámbito subjetivo de este recurso de protección tanto de los menores cuyos comportamientos disruptivos tengan por causa una alteración o deficiencia psíquica como de los menores infractores. Así, en cuanto a los primeros, el art. 26.2 LOPJM establece la imposibilidad de ingresar en estos centros a "los menores que presenten enfermedades o trastornos mentales que requieran tratamiento específico por los servicios competentes en materia de salud mental o de atención a las personas con discapacidad", para los que corresponderá el internamiento en un centro para discapacitados o en un centro de salud mental adecuado a su edad bajo las garantías del art. 763 LEC. Por lo que hace a los menores infractores, el preámbulo de la LO 8/2015 (atdo. II.11) es claro al respecto, cuando afirma que el ingreso en un centro de protección específico «no deriva de la previa acreditación de la comisión de delitos», en cuyo caso los menores a partir de los 14 años estarán sujetos a las medidas previstas en el art. 7 de la LO 5/2000, de 12 de enero, reguladora de la responsabilidad penal de los menores (en adelante, LORPM) y, entre ellas, el internamiento en un centro de reforma.

Con todo, según se desprende de la Circular FGE 2/2016 sobre el ingreso de menores con problemas de conducta en centros de protección (Fiscalía General del Estado, 2016: 8 y 15), no parece que la distinción entre los tres colectivos de menores señalados - con problemas de conducta, con trastorno mental e infractores - resulte en la práctica tan sencilla como pretende el legislador estatal, con las importantes consecuencias que, no se olvide, ello conlleva en orden a la concreta medida a adoptar, dado que puede traducirse en última instancia en el ingreso en un centro de protección específico, en un

76 Expresión también presente en el art. 5 del Decreto vasco 131/2008 y en el art. 14 del Decreto gallego 329/2005. Una expresión similar, la de «menores con conducta inadaptada", adoptan los arts. 46 y ss. de la Ley 5/2014 de Castilla-La Mancha, así como el art. 57 de la Ley valenciana 12/2008.

77 Personalmente, prefiero la denominación «menores en dificultad social» a la de «menores en conflicto social» utilizada por algunas leyes autonómicas (art. 40 de la Ley andaluza 1/1998, art. 78 de la Ley aragonesa 12/2001, art. 3.d de la Ley balear, art 83 de la Ley foral 15/2005 y art. 67 de la Ley madrileña 6/1995) por las connotaciones negativas que puede tener esta última. 
centro de salud mental o en un centro de reforma. Ello, a mi entender, por los tres motivos que se enuncian a continuación.

En primer lugar, y como ya se ha indicado, debe repararse en la propia indefinición del tipo de conductas que pueden integrar el supuesto de hecho generador del ingreso en un centro de protección específico, tal y como se configura en el art. 25 LOPJM $^{78}$.

Es de advertir, asimismo, que el cambio de denominación de que fue objeto este colectivo de menores en el último momento no ha tenido su absoluto reflejo en el régimen jurídico reservado a este recurso de protección. En este sentido, resulta elocuente la inclusión en la LOPJM de dos preceptos que hacen referencia a contingencias sanitarias ${ }^{79}$ : de una parte, el art. 25.5, que se refiere a la necesidad de continuar con los apoyos especializados o, en su caso, de adoptar otros más adecuados respecto de los menores con discapacidad ingresados en estos $\operatorname{centros}^{80}$; y de otra, el art. 33, que contempla la posible administración de medicamentos a los menores ingresados en estos centros. Ello, no se olvide, tras negar en el art. 26.1 el ingreso en estos centros de aquellos menores con enfermedades o trastornos mentales que requieran un tratamiento específico.

Por último, pese a los laudables intentos del legislador de deslindar la tipología del «menor con problemas de conducta» de la del «menor infractor», resulta innegable que los problemas de conducta de que adolecen estos menores pueden conllevar la comisión de hechos delictivos más o menos graves ${ }^{81}$.

78 Coincido así con las afirmaciones vertidas, en fase del anteproyecto de 2014, por el Consejo General del Poder Judicial (2014: 25) y el Consejo Económico y Social (2014: 13) y, tras la aprobación de la LO 8/2016, por la Fiscalía General del Estado (2016: 9 y 11-12).

79 Como pone de relieve la Fiscalía General del Estado (2016: 9-10).

80 En mi opinión, el art. 25.5 LOPJM, incorporado durante la tramitación parlamentaria del proyecto de ley, no está exento de peligro, ya que abre la puerta al ingreso en los centros de protección específicos de aquellos menores que sufran un trastorno mental no profundo, cuando esto precisamente fue lo que intentaron evitar los redactores del proyecto al suprimir la previsión del art. 26.3 del anteproyecto de 2014, referente a la imposibilidad de ingresar en estos centros a los menores con enfermedades o deficiencias mentales graves que requiriesen tratamiento específico.

81 Como reconoce, igualmente, Díez García (2010: 237). En caso de que los progenitores víctimas de violencia filioparental no denuncien y no haya prueba ajena a ellos — por ejemplo, testigos o partes médicos - que permita seguir instruyendo e investigando, el art. 16 LORPM faculta al Ministerio Fiscal, si el hecho no es grave y no hay antecedentes, para archivar las diligencias preliminares - todavía no se ha incoado expediente de reforma- por falta de acreditación de los hechos, el principio de oportunidad o, en su caso, la levedad de la conducta (Fiscalía de la AP de Zaragoza). 
De hecho, así se trasluce del propio preámbulo de la LO 8/2015 cuando hace alusión a los comportamientos agresivos de estos menores, que les pueden llevar a incurrir, en particular, en violencia filioparental (apdo. II.9) ${ }^{82}$. A partir de ahí, cuando los comportamientos gravemente disruptivos sean susceptibles de subsunción penal, la aplicación de la medida de protección contemplada en los arts. 25 y ss. LOPJM o, en su caso, de las medidas previstas en el art. 7 LORPM dependerá en buena medida de la voluntad de los terceros afectados - habitualmente, los propios progenitores-; esto es, que se decidan a interponer o no la oportuna denuncia contra el menor ante el Ministerio Fiscal ex art. 16 LORPM $^{83}$. Junto a ello conviene tener presente que solo los menores entre 14 y 18 años son imputables penalmente (art. 1 LORPM) y, por consiguiente, solo a estos se les podrán aplicar las medidas reservadas a los menores infractores, entre las que se encuentra el internamiento en un centro de reforma o, en su caso, terapéutico si adolecen de anomalías o alteraciones psíquicas (art. 7, letras a-d LORPM) ${ }^{84}$. En cambio, para los menores de 14 años, desde el momento en que no incurren en responsabilidad penal, el art. 3 LORPM prevé exclusivamente la aplicación de «lo dispuesto en las normas sobre protección de menores». A tal fin, según establece el precitado precepto, el Ministerio Fiscal habrá de remitir — siempre que lo considere justificado: Circulares FGE 1/2000, 1/2010 y 2/2016— ${ }^{85}$, a la Entidad Pública

82 Resulta revelador en este sentido que el art. 78 de la Ley aragonesa 12/2001 y el art. 14.1 del Decreto gallego 329/2005 equiparen ambas categorías de menores a los efectos de dispensarles el mismo tratamiento por parte de la Administración.

83 A este respecto, interesa reparar en el importante incremento desde 2013 del número de denuncias de padres a hijos por violencia filioparental, según datos proporcionados en el «Informe sobre violencia filioparental» elaborado por la Fundación Amigó (2017: 5). Ello no obstante, según consta en el mismo informe, solo se denuncian los casos más graves, entre un $10 \%$ y un $15 \%$ del total, quedando así el problema oculto en la mayor parte de las ocasiones.

84 Con todo, para aquellos casos en que los actos delictivos se circunscriben al entorno familiar, la Fiscalía General del Estado (circular 2010: 34) aconseja acudir preferentemente a medidas no privativas de libertad, tales como la convivencia con grupo familiar o educativo, libertad vigilada o alejamiento, a complementar en muchos casos con la de tratamiento terapéutico de tipo ambulatorio.

85 Sobre este particular, la Fiscalía General del Estado (2016: 16-17) aclara que tal remisión de testimonio no es un «trámite inexcusable», de tal manera que deberá obviarse cuando «por la escasa entidad de los hechos, por la suficiencia de la corrección en el ámbito familiar o educativo y por las circunstancias del menor no se detecte la necesidad de articular los recursos previstos civilmente para su protección». La misma Fiscalía, ya con anterioridad (2010: 3), matizó el tenor del art. 3 LORPM, para enten- 
el oportuno testimonio para que esta promueva las medidas de protección oportunas, entre las que no cabe descartar como último recurso el ingreso del menor en un centro de protección específico, siempre que asuma su guarda o tutela ex art. 25.1 LOPJM ${ }^{86}$. De este modo, la intención del legislador de dispensar un tratamiento distinto a ambos perfiles de menores puede quedar un tanto difuminada en la práctica con los riesgos que ello implica ${ }^{87}$.

\subsection{La importancia del diagnóstico}

Ante esta confusa situación, se revela fundamental el diagnóstico de los menores a fin de determinar su condición específica de «menores con problemas de conducta» $y$, por ende, excluir la existencia de un trastorno mental que prive al menor de la capacidad necesaria para comprender el alcance de sus $\operatorname{actos}^{88}$, según resulta del propio tenor del art. 25.1.2 LOPJM («menores diagnosticados» $)^{89}$. Cuestión diferente es que la noción de "diagnóstico» no deje de plantear, asimismo, importantes dudas, como advierte la Circular FGE $2 / 2016^{90}$.

der que lo que realmente corresponde al fiscal en tal caso es «valorar la procedencia» de una intervención en el ámbito de la protección de menores. Véanse en términos similares su Circular 1/2010 (4).

86 Véase en términos similares García Pérez (2018: 9). Por lo demás, entiéndase como «último recurso», porque, al menos en lo que atañe a la Comunidad Autónoma de Aragón, desde hace unos años existe en el marco de la protección de menores el EMCA (Equipo de Atención Educativa a Menores de 14 años) con la misión de realizar una intervención educativa individualizada con estos menores infractores, implicando para ello a su entorno familiar (disponible en: https://bit.ly/2KtXSfB).

87 Sobre este particular, la Fiscalía General del Estado (2016: 15) se refiere al «peligro de incurrir en fraude de etiquetas con el sistema de responsabilidad penal del menor». Que este riesgo es real se desprende de una las comparecencias a la Comisión especial del Senado (acta de la sesión de 13 de junio de 2011: 14), donde se afirmó que los centros de protección específicos son «centros destinados a menores que no han infringido la ley o que, si la han infringido, no están ingresados en estos centros en razón de la infracción cometida» (la cursiva es nuestra).

88 En palabras de Díez García 82010:238), con base en la STS de 3 de diciembre de 2009.

89 Reparan, asimismo, en la importancia del diagnóstico diversas comparecencias en la Comisión especial del Senado (acta de las sesiones de 28 de marzo de 2011: 27 y de 4 de abril de 2011: 16); y, en el plano doctrinal, Díez García (2010: 229) y Vázquez-Pastor Jiménez (2016: 145).

90 Fiscalía General del Estado (2016: 7). Véase en el mismo sentido Ferreirós Marcos (2017: 18). 
Sí parece desprenderse de la lectura conjunta de los arts. 26 LOPJM y 778 bis LEC que tal diagnóstico opera en dos momentos distintos ${ }^{91}$. Con carácter previo, a la hora de evaluar por parte de la Entidad Pública o del Ministerio Fiscal qué concreta intervención procede en función del perfil del menor. Así, los arts. 26.1 LOPJM y 778 bis. 1 LEC exigen que la solicitud de ingreso en un centro de protección específico, ya provenga de la Entidad Pública o del Ministerio Fiscal, se acompañe de una «valoración psicosocial» del menor que justifique la adopción de la medida de protección que nos ocupa y no de otra distinta $^{92}$. En un segundo momento, según dispone el art. 778 bis.4, $2^{a}$ parte LEC, durante la tramitación del procedimiento judicial dirigido a su adopción, el juez, por su parte, habrá de recabar «el dictamen de un facultativo», al objeto de decidir si autoriza o no el ingreso.

La terminología legal empleada, sin embargo, no es plenamente coincidente, en cuanto que la expresión «dictamen de un facultativo» parece evocar exclusivamente la intervención de un profesional del ámbito de la salud, mientras que el término «valoración psicosocial» parece tener un significado más amplio que el estrictamente sanitario ${ }^{93}$. Ante esta confusión, la Circular 2/2016 FGE ha optado por una interpretación amplia en aras de la mayor imparcialidad, recomendando, de modo acorde con las Directrices del Consejo de Ministros del Consejo de Europa sobre justicia adaptada a los niños de 2010, que tanto la solicitud de ingreso como su autorización judicial estén fundamentadas en un informe de carácter multidisciplinar ${ }^{94}$. Según parece derivarse de la propia terminología legal («informe o valoración psicosocial»), tal informe habrá de emitirse conjuntamente por psicólogos, educadores y trabajadores sociales, pero también, a mi juicio, por médicos psiquiatras, en cuanto su intervención resulta esencial para detectar cuándo un problema de conducta esconde un trastorno mental ${ }^{95}$. Por añadidura será «especializado» en el sentido de que habrá de efectuarse por personal especializado en menores, tal y como matiza el art. 26.1 in fine LOPJM ${ }^{96}$.

91 De acuerdo con la Fiscalía General del Estado (2016: 8-9).

92 Nótese, sin embargo, que tal informe no se exige sorprendentemente en el caso de los ingresos urgentes acordados por la Entidad Pública o el Ministerio Fiscal y a ratificar ulteriormente por el juez, sustituyéndose por la mera «información de que se disponga y justificante del ingreso inmediato" (art. 26.3.2 LOPJM).

93 De acuerdo con la Fiscalía General del Estado (2016: 9).

94 Fiscalía General del Estado (2016: 10 y 29-30) y Consejo de Ministros del Consejo de Europa (2010: apdo. IV, reglas 16 a 18).

95 En términos similares se expresa García Díez (2016: 7).

96 Ya sean los equipos técnicos adscritos bien a la Entidad Pública de protección de menores a los que se refiere específicamente el art. 25.1 LOPJM, bien a los juzgados, 


\subsection{La falta de previsión legal sobre la edad mínima para aplicar esta medida de protección}

No puede cerrarse este epígrafe dedicado al ámbito subjetivo del acogimiento residencial de menores con problemas de conducta sin reparar en la ausencia de un límite de edad mínimo respecto a los menores a los que está dirigido, lo que, a mi juicio, hubiera sido muy necesario en atención a las medidas de restricción de derechos fundamentales y aun sanciones que pueden aplicárseles en su caso. En efecto, ni los arts. 25 y ss. LOPJM ni el art. 778 bis LEC determinan franja de edad alguna para aplicar este recurso, discrepando así del planteamiento adoptado por algunas leyes autonómicas de protección de menores, que acertadamente reservan esta medida a los menores que hayan cumplido, al menos, 12 años ${ }^{97}$. Ello no deja de resultar llamativo cuando el legislador estatal en 2015 se preocupó, en cambio, de excluir expresamente el acogimiento residencial para los menores de 3 años, como regla —esto es, salvo en caso de imposibilidad debidamente acreditada o falta de conveniencia del acogimiento familiar- y de fijar una duración máxima de tres meses al acogimiento residencial de los menores de 6 años (art. 21.3 LOPJM). Esta circunstancia, de hecho, ha sido denunciada por la Fiscalía General del Estado en su Circular 2/2016, para imponer a los fiscales el deber de vigilar especialmente los ingresos en estos centros especiales de menores con edad inferior a 12 años, en cuanto «no parece aceptable» (Fiscalía General del Estado, 2016: $17-18)^{98}$.

\section{FINALIDAD}

El examen de la finalidad de la medida aquí estudiada pasa necesariamente por recalcar su carácter de acogimiento residencial, según resulta de la propia rúbrica del art. 25 LOPJM, y, por ende, su pertenencia al ámbito de la

según indica la Fiscalía General del Estado (2016: 30). Sobre este particular interesa dar noticia de la existencia de un proyecto de real decreto de 17 de enero de 2018 por el que se crea la especialidad en psiquiatría del niño y adolescente, muy necesaria para abordar la concreta problemática que nos ocupa, como advirtió en su momento el Defensor del Pueblo (2009: 19).

97 En concreto, fijan la edad mínima de 12 años el art. 67 de la Ley madrileña 6/1995, el art. 9.1 del Decreto asturiano 48/2003 y el art. 6.i del Decreto 37/2004 de Castilla y León. Eleva la edad a 13 años el art. 5.2 del Decreto vasco 131/2008.

98 Tal indefinición ya fue puesta de relieve, en fase del anteproyecto de 2014, por el Consejo Económico y Social (2014: 13), sin que fuera objeto de ulterior rectificación ni en el proyecto de ley ni en el texto definitivamente aprobado. 
protección de menores. De ello resulta —e insisto en la idea- que los centros reservados a los menores con problemas de conducta, aun específicos, son centros de protección y no establecimientos para la ejecución de medidas privativas de libertad impuestas a menores infractores, como advierte la Circular FGE 2/2016 (Fiscalía General del Estado, 2016: 18)99. Pero, y aquí radica su divergencia con los centros ordinarios de protección, a la par que se prevé su carácter asistencial y educativo (art. 25.2, en relación con los arts. 11.2.f y 21 LOPJM ${ }^{100}$, se contemplan diversas medidas que implican importantes restricciones de derechos fundamentales y un régimen disciplinario, en atención al especial perfil de sus usuarios (arts. 27 a 31 LOPJM). A partir de ahí, si bien comparto la opinión de quienes afirman que la situación de los menores con problemas de conducta demanda soluciones diferentes a las que ofrecen los centros de protección ordinarios ${ }^{101}$, en todo caso considero que deben primar las soluciones educativas, so riesgo de que estos centros se empleen como instrumentos de defensa social frente a menores conflictivos - como advierte el propio preámbulo de la LO 8/2015, aptdo. II.9- ${ }^{102} \mathrm{y}$, por ende, queden difuminados los caracteres que los distinguen de los centros de reforma ${ }^{103}$.

En este orden de cosas, es de valorar muy positivamente la reiterada mención a la finalidad educativa de este recurso por la LOPJM, en particular en sus arts. 25.2 in fine, 27.1 y $31.2^{104}$. No obstante lo anterior, hubiera sido deseable una regulación más exhaustiva de su vertiente educativa ${ }^{105}$, toda vez que el legislador estatal se ha limitado a incluir una mención del «proyecto educativo»

99 Esta idea estuvo también presente en las comparecencias a la Comisión especial del Senado (actas de las sesiones de 28 de marzo de 2011: 28 y de 13 junio 2011: 5).

100 A este respecto, Galán Rodríguez (2013: 28) señala como elementos clave en la intervención con menores con problemas de conducta el cuidado sustituto y la intervención socioeducativa, en un planteamiento coincidente con los recursos ordinarios de protección.

101 Entre otros, Fiscalía General del Estado (Memoria 2010: 973) y Observatorio de la Infancia en Andalucía (2012: 32); y, en la doctrina, March (2007: 215-216), Galán Rodríguez (2013: 23) y Berrocal Lanzarot (2017: 278).

102 En los mismos términos se expresó en su momento la Fiscalía General del Estado (Memoria 2010: 973).

103 Ya con anterioridad a la LO 8/2015 advirtió de este riesgo Díez García (2010: 277278).

104 Previsión acorde con lo dispuesto en el art. 5.1.d del Convenio Europeo de Derechos Humanos de 1950.

105 Como recomendó de lege ferenda la Fiscalía General del Estado (Memoria 2010: 976) y, ya en fase del anteproyecto de 2014, el Consejo Económico y Social (2014: 2014), el Consejo de Estado (2014: 27-28), el Consejo Fiscal (2014: 13) y el Consejo Gene- 
con el que deben contar todos los centros de protección de menores sin mayor concreción en orden a su contenido (arts. 25.2 y 31.1 LOPJM) ${ }^{106}$, lo que resulta llamativo si se compara con la detallada regulación que ofrece, sin embargo, la LOPJM tras la reforma de 2015 sobre otras cuestiones atinentes al acogimiento, como pueden ser los extremos del documento anexo a acompañar a la resolución administrativa de constitución del acogimiento familiar (art. 20.3). De hecho, a la importancia del proyecto educativo se refirió en su momento el Protocolo básico (2010), para señalar que no solo constituye la finalidad de los centros, sino que se erige en único presupuesto de validez de las medidas de seguridad y del régimen disciplinario ${ }^{107}$. Ello sin olvidar la obligación de los centros, contemplada en el art. 21.1.b LOPJM, de diseñar a cada menor un plan individualizado de intervención educativa con unas fases bien definidas - recepción, observación, educación, tratamiento especial, evaluación y periodo posinstitucional- y unas técnicas específicas dirigidas al cumplimiento de los objetivos fijados, en atención a sus características individuales y a las relaciones que mantenga con sus contextos de referencia; plan que, por añadidura, habrá de revisarse periódicamente $(21.1 .1 \text { LOPJM })^{108}$. En cualquier caso, dado el perfil de estos menores, el término «educación» debe entenderse más allá del plano formativo, para abordar la normalización de su conducta ex art. 25.2 LOPJM, en el sentido de proporcionarles las estrategias necesarias para normalizar su relación con su entorno familiar y social y potenciar aquellas habilidades que mejoren su desarrollo personal.

Junto a la finalidad educativa, el art. 25.2 LOPJM se refiere, asimismo, a la «necesidad de proporcionar un marco adecuado para la reintegración familiar», lo que constituye el objetivo último de la intervención de la Administración en el ámbito de la protección de menores, de conformidad con lo dispuesto en los arts. 11.2.c LOPJM y 172.4 CC. Se trata así de promover la desinstitucionalización y acortar en la medida de lo posible el ingreso de

ral del Poder Judicial (2014: 25). No obstante, tales recomendaciones fueron obviadas tanto en el proyecto de ley como en el texto definitivamente aprobado.

106 Según resulta de la lectura de la normativa autonómica de protección de menores (por ejemplo, el art. 51 del Decreto 40/2000, por el que se aprueba el Reglamento de organización y funcionamiento de los centros de atención a menores en el ámbito de la Comunidad Autónoma Canaria), el proyecto educativo de todo centro de protección de menores es esencial, en cuanto define las notas de identidad de centro, formula los objetivos generales perseguidos y especifica la metodología de trabajo educativo.

107 Comisión Interautonómica de Directores Generales de la Infancia (2010: 10). Véase en el mismo sentido la Fiscalía General del Estado (2011: 35).

108 Comisión Interautonómica de Directores Generales de la Infancia (2010: 10-11) y Comité de Ministros del Consejo de Europa (2005: apdo. III, regla 4). 
los menores en tales centros, de forma que sus familias puedan reintegrarlos en su núcleo de convivencia. Para ello es fundamental el ya referido programa educativo a desarrollar con los menores destinatarios de la medida, pero también la implicación de las familias, para dotarles de las herramientas educativas necesarias para atender a las dificultades de sus hijos y facilitar su retorno familiar cuando sea lo más adecuado a su interés superior ${ }^{109}$. Una lectura detenida del marco normativo de este recurso pone de manifiesto, sin embargo, la existencia de ciertas dificultades en orden a la consecución de este objetivo. Así, en primer lugar se advierte que a los progenitores o, en su caso, el tutor ordinario no se les implica en el procedimiento dirigido a obtener la necesaria autorización judicial para el ingreso del menor en el centro más allá de darles audiencia, y ello siempre que ostenten la patria potestad o tutela (art. 778 bis. 4 LEC). De este modo, el régimen vigente omite toda referencia a la necesaria notificación a los progenitores o tutor de la correspondiente resolución judicial cara la interposición, en su caso, del recurso en apelación $y$, por añadidura, no les reconoce un derecho explícito a ser informados sobre el contenido del acogimiento residencial, obviando así las Reglas de las Naciones Unidas para la protección de los menores privados de libertad de 1990 y las Directrices del Comité de Ministros del Consejo de Europa sobre justicia adaptada a los niños de $2010^{110}$.

En segundo lugar, sorprende que, solo en caso de que los progenitores hayan solicitado voluntariamente la constitución de la guarda, se prevea que asuman el compromiso de someterse a intervención profesional (art. 25.3 LOPJM); no, en cambio, en el supuesto de guarda constituida judicialmente siendo sus presupuestos los mismos, ni tampoco en el de tutela administrativa cuando la adopción de esta medida no excluye el posible retorno del menor con su familia, si es conforme a su interés (art. 172.3 CC). Es más, adviértase

109 Defensor del Pueblo (2009: 51-52) y Comisión Interautonómica de Directores Generales de la Infancia (2010: 11-12).

110 Asamblea General de Naciones Unidas (1990: regla 22) y Comité de Ministros del Consejo de Europa (2010: apdo. IV, reglas 1 y 3). Este derecho de información a los progenitores, sin embargo, se encuentra reconocido expresamente por algunas normas autonómicas (véase por ejemplo el art. 13 del Decreto andaluz 355/2003 de acogimiento residencial de menores y el art. 59 del Decreto 131/3003 de Castilla y León por el que se regula la acción de protección de los menores de edad en situación de riesgo o de desamparo), así como por la Comisión Interautonómica de Directores Generales de la Infancia (2010: 6). Con todo, el art. 22 LOPJM impone a la Administración tutora o guardadora un deber genérico de información a los progenitores, tutores o guardadores sobre la situación de los menores, salvo resolución judicial en contrario. 
que solo se exige el mero compromiso de la familia de someterse a intervención, cuando quizá hubiese sido más eficaz imponer a los progenitores la obligación de implicarse en el proceso de restructuración de su relación paterno-filial. Con todo, la falta de colaboración por parte de los progenitores podrá considerarse indicativa de un inadecuado cumplimiento de sus deberes de protección y, por ende, conllevar la declaración de desamparo, de conformidad con lo dispuesto en el art. 172 bis, en relación con el art. 172.1.2 CC.

Por último, no deja de ser preocupante que, cuando a los menores se les imponen medidas de seguridad en el centro, los progenitores o, en su caso, el tutor ordinario sean excluidos no solo de los sujetos a quienes debe que notificarse su adopción, sino de los legitimados para recurrirlas, según resulta de la lectura del art. 27.3 LOPJM.

\section{MEDIDAS RESTRICTIVAS DE DERECHOS FUNDAMENTALES}

Como se viene insistiendo, más allá de la finalidad asistencial y educativa que comparten con los centros de protección ordinarios, los centros específicos de menores con problemas de conducta presentan como singularidad la posible utilización de medidas de restricción de derechos fundamentales, dado el especial perfil de los menores a quienes van dirigidos: menores con comportamientos disruptivos, que tienen una seria dificultad para acatar las normas, lo que puede generar importantes riesgos para la seguridad tanto de los propios menores como del personal que desarrolla su actividad en el centro. Es precisamente esta vertiente la que más ha cuidado la reforma de 2015, sin duda consciente de la importancia de delimitar las posibles medidas a adoptar, así como su forma y momento de ejecución, con la finalidad de distinguir netamente estos centros — que no se olvide, son centros de protección y, en todo caso, abiertos ${ }^{111}$ — de los centros de reforma destinados a los menores infractores. Ciertamente, una lectura precipitada, de una parte, de los arts. 27 a 31 LOPJM; y, de otra, de los arts. 40 a 55 del Reglamento de la Ley Orgánica reguladora de la responsabilidad penal del menor (Real Decreto $1774 / 2004$ ) puede llevar a incurrir en confusión entre ambos recursos, el uno de protección y el otro de reforma, dado que las medidas previstas para

111 Como se recalcó en la Comisión especial del Senado (actas de las sesiones de 28 de marzo de 2011: 18 y de 13 de junio de 2011: 15) y ulteriormente la Fiscalía General del Estado (2016: 13 y 18). Por ello, no creo que puedan calificarse de centros privativos de libertad, como sostiene Martín Azcano (2015: 3-4), sino más bien con posibles restricciones de salidas, entre otras medidas limitativas de derechos fundamentales. Participa de la opinión que aquí se sustenta Gómez Aparicio (2013: 280). 
ambos vienen a ser coincidentes ${ }^{112}$. Pero, en todo caso, se debe tener presente la distinta finalidad que persiguen: los centros específicos de protección, una finalidad exclusivamente educativa; y los centros de reforma, adicionalmente una finalidad sancionatoria, como resulta de la propia lectura de la exposición de motivos de la LORPM (apdo. 7) ${ }^{113}$. En particular, la LOPJM contempla como posibles medidas que inciden en los derechos fundamentales de los menores, de una parte, la adopción de medidas de seguridad (arts. 27 a 30) y, de otra, la restricción en el régimen de visitas y de comunicaciones con familiares y allegados y en los permisos de salida (arts. 34 y 35). En cualquier caso, se atribuye a ambas una finalidad educativa (arts. 27.1, 34.1 y 35.1$)^{114}$, de tal manera que no forman parte del régimen disciplinario con el que deben contar adicionalmente estos centros (art. 31). Por añadidura, un examen por separado de las mismas permite constatar el importante esfuerzo desplegado por el legislador estatal para dotarlas de las precisas garantías, al objeto de su debida adecuación a los postulados constitucionales y las recomendaciones provenientes de diversas instancias internacionales ${ }^{115}$; ello sin perjuicio de algunas deficiencias detectadas, como se expondrá a continuación.

\subsection{Medidas de seguridad}

De acuerdo con el art. 27.1.1 LOPJM, las medidas de seguridad pueden responder a una triple tipología: la contención, el aislamiento y los registros personales y materiales. Acto seguido y antes de abordar el régimen específico de cada una de ellas, el mismo precepto formula una serie de previsiones genéricas dirigidas, en buena medida, a evitar un uso arbitrario y abusivo de las mismas. Así, en sus apdos. 1.2, 2 y 4 se refiere a su finalidad educativa, que no disciplinaria, como matiza el art. 31.3; a su sujeción a los principios

112 Como advirtió, en fase del anteproyecto de 2014, el Consejo Económico y Social (2014: 14) y, en la doctrina, Gómez Aparicio (2013: nota 51).

113 Por esta razón, y ante la innegable realidad de la conflictividad y agresividad de que adolecen estos menores — debidamente contrastada con técnicos del IASS—, no puedo compartir la opinión de Díez García (2010: 277), cuando identifica las medidas de corrección a aplicar por los centros específicos de protección con medidas sancionatorias en sentido estricto y, por ende, niega su justificación.

114 Haciéndose eco de las recomendaciones del Defensor del Pueblo (2009: 411), de la Fiscalía General del Estado (Memoria 2010:978) y del Consejo de Estado (2014: 32) en fase del anteproyecto de 2014.

115 Asamblea General de Naciones Unidas (1990: reglas 63-71), Comité de los Derechos del Niño de Naciones Unidas (2006: recomendaciones 32-35) y Comité de Ministros del Consejo de Europa (2005: apdo. II, regla 8). 
de excepcionalidad — como «último recurso»—, de necesidad — «en defensa propia o en casos de intento de fuga, resistencia física a una orden, riesgo directo de autolesión o lesión a terceros, o daños graves a la propiedad»—, de proporcionalidad y prohibición de exceso — aplicación con «la mínima intensidad posible»— y de provisionalidad — «duración necesariamente limitada en el tiempo»—; al necesario respeto a los derechos fundamentales del menor, con expresa alusión a su dignidad y privacidad; a su ejecución por personal especializado en protección de menores; y a su necesaria inscripción en el libro registro de incidencias con el que deben contar los centros de acogimiento residencial, conforme al art. 21.2.2 LOPJM $^{116}$. La competencia para adoptar estas medidas se atribuye al director del centro o persona en quien haya delegado, previsión esta, sin duda, razonable en aras de la celeridad requerida en su aplicación. Ahora bien, con ánimo abiertamente garantista, se prevé la inmediata notificación de su decisión a la Entidad Pública y al Ministerio Fiscal, quienes, en su caso, podrán recurrirla ante el juez autorizante del ingreso, al igual que el propio menor que haya sido objeto de la medida adoptada. No se reconoce legitimación, sin embargo, para recurrirla a los progenitores o tutores, lo que no deja de ser cuestionable y más cuando mantengan la titularidad de la patria potestad o, en su caso, de la tutela ordinaria, por haber asumido la Entidad Pública la mera guarda administrativa. Tampoco se fija plazo alguno para formalizar el oportuno recurso, por lo que entiendo que habrá que acudir al de dos meses a contar desde la notificación del art. 780.1 LEC, referido genéricamente a la oposición a las resoluciones administrativas en materia de protección de menores, aunque la decisión del director del centro carezca propiamente de tal naturaleza.

\section{a) Medidas de contención}

Como primera modalidad de medidas de seguridad, el art. 28 LOPJM prevé la posible adopción de la contención, medida esta con abierta incidencia en la libertad e integridad física de los menores, reconocidos como derechos fundamentales en los arts. 17 y $15 \mathrm{CE}$, respectivamente. Ciertamente, el término «contención» en el contexto que nos ocupa puede tener connotaciones negativas, vinculándolo a maltrato o vejaciones. No obstante, resulta innegable que la normalización de la conducta de los menores conlleva la necesidad

116 Se recogen así las diversas recomendaciones vertidas durante los trabajos preparatorios por la Comisión especial del Senado (acta de la sesión de 28 de marzo de 2011: 22), el Consejo de Estado (2014: 31-32), el Consejo Económico y Social (2014: 14), el Consejo Fiscal (2014:15) y el Consejo General del Poder Judicial (2014: 28). 
de poner límites cuando tienen conductas destructivas y violentas ${ }^{117}$. Por ello, la contención puede ser necesaria en casos urgentes y, como prevén los apdos. 1 y 2 del precitado precepto, siempre con arreglo el siguiente orden, en función de la gravedad de los hechos: primero, verbal y emocional; segundo, física — desde la interposición entre el menor y la persona o el objeto en peligro hasta la inmovilización física, pasando por la restricción de movimientos: art. 28.3-; y, por último, mecánica ${ }^{118}$. Con todo, no deja de parecerme poco acorde con la finalidad educativa de estas medidas la admisión de la contención mecánica, y más sin precisar sus modalidades, lo que, a mi juicio, hubiera sido muy oportuno al objeto de su debida distinción de la contención reservada a los centros de reforma por el art. 55.2 del Reglamento de la LORPM ${ }^{119}$. Sí, en cambio, se han incluido certeramente previsiones acerca de cuándo y cómo será admisible tal modalidad de contención. Así, de la lectura conjunta de sus apdos. 1 y 4 resulta que se trata de una medida a aplicar en último lugar por equipos homologados y bajo estricto protocolo ${ }^{120}$, exclusivamente "para evitar grave riesgo para la vida o integridad física del menor o de terceros» $\mathrm{y}$ «siempre que no sea posible reducir el nivel de estrés o trastorno del menor por otros medios».

b) Aislamiento del menor

Asimismo, de modo necesariamente restrictivo se regula en el art. 29 LOPJM el posible aislamiento del menor mediante su permanencia en un espacio del que se impida su salida, desde el momento en que conlleva una

117 En palabras de Galán Rodríguez (2013: 28). Véase, en el mismo sentido, Comisión especial del Senado (acta de la sesión de 7 de marzo de 2011: 14).

118 Se excluye, sin embargo, con buen criterio la contención farmacológica, toda vez que el art. 33 LOPJM circunscribe la administración de medicamentos al supuesto en que sean necesarios para la salud del menor, con el debido respeto a las previsiones legales sobre consentimiento informado y bajo la supervisión de un médico autorizado. La reforma de 2015 ha seguido así las pautas de la Asamblea General de Naciones Unidas (1990: regla 55), posteriormente asumidas por la Comisión Interautonómica de Directores Generales de la Infancia (2010: 16).

119 Resulta significativo a este respecto que tal modalidad de contención no fuese incluida en el Protocolo básico de la Comisión Interautonómica de Directores Generales de la Infancia (2010: 16). Cuestiona, asimismo, la contención mecánica Galán Rodríguez (2013: 29), por considerar que poco contribuye al desarrollo de mecanismos de autorregulación por parte del menor.

${ }^{120}$ Como se recomendó en la Comisión especial del Senado (acta de la sesión de 7 de marzo de 2011: 14). 
importante restricción de su derecho a la libertad personal reconocido en el art. $17 \mathrm{CE}$. Así, esta medida solo podrá usarse puntualmente en prevención de actos violentos, en particular, de autolesiones o lesiones a otros menores residentes, al personal del centro o terceros o de daños graves a sus instalaciones y, entiendo, al único objeto de tranquilizar al menor, sin que deba confundirse con la sanción de separación prevista en el art. 66 del Reglamento de la LORPM ${ }^{121}$. Por añadidura, con un claro propósito garantista se fija la duración máxima de esta medida —-máximo seis horas—, el lugar de cumplimiento — preferentemente en la habitación del menor y, de no ser posible, en un espacio de similar habitabilidad y dimensiones- y las condiciones de ejecución —bajo la compañía o supervisión de un educador- ${ }^{122}$.

c) Registros personales y materiales

Como tercera modalidad de medidas de seguridad, el art. 30 LOPJM prevé la práctica de registros dirigidos a detectar la existencia en el centro de objetos y sustancias prohibidas que puedan constituir un grave riesgo para su seguridad y la del propio menor ${ }^{123}$. Estos registros pueden ser personales y materiales y, en todo caso, se deberán llevar a cabo con el debido respeto a los derechos fundamentales del menor y, entre ellos particularmente, según precisa su apdo. 1, a los derechos a su dignidad personal e intimidad personal reconocidos por los arts. 10 y $18 \mathrm{CE}$. El registro personal o cacheo se realiza sobre la propia persona del menor, preferentemente con medios electrónicos. $\mathrm{Su}$ puesta en práctica requiere un mínimo de dos profesionales del mismo sexo que el menor. Cuando el registro implique alguna exposición corporal, se efectuará «en un lugar adecuado» y sin la presencia de otros menores, en aras de su privacidad (art. 30.2). Por su parte, el registro material tiene por objeto las pertenencias del menor — previa comunicación, de no poder efectuarse en su presencia-, pudiendo retirarle aquellas que sean de ilícita procedencia, resulten dañinas para las personas o instalaciones del centro o no estén autorizadas para menores de edad (art. 30.3) ${ }^{124}$.

121 Según consta en una de las comparecencias en la Comisión especial del Senado (acta de la sesión de 28 de marzo de 2011: 23).

122 Se regula así esta medida conforme a las recomendaciones del Defensor del Pueblo (2009: 413), la Comisión Interautonómica de Directores Generales de la Infancia (2010: 17-18), la Fiscalía General del Estado (memoria 2010: 978) y, en fase del anteproyecto de 2014, por el Consejo de Estado (2014: 33).

123 De acuerdo con Vázquez-Pastor Jiménez (2016: 153).

124 Tales previsiones siguen las pautas de la Comisión Interautonómica de Directores Generales de la Infancia (2010: 14), así como las recomendaciones del Defensor del 


\subsection{Restricciones en el régimen de visitas y de comunicaciones con familiares y allegados $y$ en los permisos de salida}

Una segunda medida que afecta a los derechos fundamentales de los menores ingresados en estos centros tiene que ver con la restricción o, en su caso, suspensión del régimen de visitas y comunicaciones con sus parientes y allegados, así como de los permisos de salida; posibilidad esta prevista en los arts. 34 y 35.2 LOPJM. Al igual que las medidas de seguridad, esta medida parece contemplarse como algo excepcional, teniendo presente la finalidad exclusivamente educativa de este recurso y «conforme a los términos recogidos en la autorización judicial de ingreso» (arts. 34.1.1 y 35.2 LOPJM). Ahora bien, esta última expresión no puede inducir a error en el sentido de que se reconozca la competencia sobre esta materia al juez ${ }^{125}$, ya que, según resulta del art. 26.3 LOPJM, el auto de autorización de ingreso solo habrá de pronunciarse sobre la "posibilidad de limitarles temporalmente el régimen de visitas, comunicaciones y salidas». Y ni siquiera a la Entidad Pública que tiene atribuida la tutela o guarda, como contemplaba alternativamente el Protocolo básico $(2010)^{126}$. En su lugar, esta facultad se ha atribuido al director del centro -independientemente de su titularidad pública o privada - como excepción al régimen de los arts. 160 y $161 \mathrm{CC}$ en materia de visitas y comunicaciones de los menores acogidos ${ }^{127}$, lo que me parece excesivo en atención a las importantes implicaciones de esta decisión en orden a los derechos del menor a la libertad del art. $17 \mathrm{CE}$ y a relacionarse con su familia de origen de los arts. 160.1 CC y 21 bis.1.d LOPJM ${ }^{128}$, y ello más aún si se repara en el dato según el cual en los centros de reforma la última palabra sobre este

Pueblo (2009: 411 y 2014: 7) y de la Fiscalía General del Estado (Memoria 2010: 978).

125 Lo que recomendó, en su momento, el Defensor del Pueblo (2009: 409).

126 Comisión Interautonómica de Directores Generales de la Infancia (2010: 14).

127 Como, asimismo, advierte la Fiscalía General del Estado (2016: 38-39). A mi entender, de la lectura conjunta de los arts. 160 y 161 CC, en su redacción dada por la Ley $26 / 2015$, resulta que la competencia para fijar y suspender el régimen de visitas de los menores en situación de tutela administrativa corresponde a la Entidad Pública, mientras que, tratándose de menores en situación de guarda administrativa, sigue estando atribuida a la autoridad judicial.

128 Puede traerse a colación, asimismo, la recomendación del Comité de Ministros del Consejo de Europa (2005: apdo. III, regla 1) atinente a que los centros de protección estuviesen organizados de forma tal que "permitiesen el mantenimiento de contactos regulares entre los progenitores y el hijo». 
extremo la tiene el juez ex art. 40.7 del Reglamento de la LORPM, al menos en lo que hace a su suspensión ${ }^{129}$.

En cualquier caso, tal decisión - necesariamente motivada ex arts. 34.1 y 35.2 LOPJM - es recurrible ante la jurisdicción civil, en particular ante el órgano judicial que autorizó su ingreso, previa notificación a los legitimados a tal efecto. Ahora bien, aquí conviene reparar en la falta de concordancia entre los arts. 34.3 y 35.2 LOPJM a la hora de especificar las personas legitimadas en orden a este concreto recurso. Así, mientras la medida limitativa o suspensiva del régimen de visitas y de los permisos de salida solo podrá ser recurrida por el propio menor y el Ministerio Fiscal, la legitimación para recurrir la medida atinente a las comunicaciones se atribuye adicionalmente a aquellas «personas interesadas», expresión esta donde bien pueden tener cabida la Entidad Pública, pero también los progenitores o tutor ordinario. Por lo demás, al igual que sucede con las medidas de seguridad, en ausencia de previsión expresa sobre el plazo para formalizar el oportuno recurso, entiendo que será de aplicación el de dos meses del art. 780.1 LEC.

\subsection{El régimen disciplinario}

Otra singularidad de los centros de protección específicos radica en el régimen disciplinario del que deben dotarse, además del régimen interno de convivencia y funcionamiento común a todos los acogimientos residenciales (art. 31, en relación con el art. 21.1.g LOPJM). Ahora bien, el tenor del art. 31 LOPJM revela, a mi juicio, que el legislador estatal ha sido menos cuidadoso en la regulación de este extremo que en el concerniente a las medidas restrictivas de derechos fundamentales, toda vez que ha prescindido de fijar el contenido del régimen disciplinario en lo que hace a las posibles infracciones y sus correspondientes sanciones, así como de establecer la autoridad competente y el procedimiento a seguir, lo que hubiera sido deseable por razones de seguridad jurídica y más cuando el Reglamento de la LOPJM contiene sendas previsiones al respecto por lo que atañe a los centros de reforma (arts. 59 y ss. $)^{130}$. En su lugar, el art. 31 LOPJM se limita a establecer unas pautas

129 De hecho, en fase del anteproyecto de 2014 discreparon de esta opción legislativa el Defensor del Pueblo (2014: 8) y el Consejo General del Poder Judicial (2014: 31-32) para defender, en su lugar, la competencia judicial.

130 Se hace así caso omiso a las recomendaciones vertidas por la Asamblea General de las Naciones Unidas (1990: regla 68), así como, a nivel nacional, por la Fiscalía General del Estado (Memoria 2010: 977) y en las comparecencias de la Comisión especial del Senado (actas de las sesiones de 28 de marzo de 2011: 22 y de 20 de junio de 2011: 10 y 12$)$. 
mínimas a cumplir por el mismo, para remitir su desarrollo a la legislación autonómica con el consiguiente riesgo de heterogeneidad al que precisamente ha tratado de poner fin la reforma de $1015^{131}$. Se prevé así, con ánimo abiertamente garantista, que el régimen disciplinario deberá fundarse en el proyecto educativo del centro y en el plan individualizado de intervención educativa de cada menor; que será el último recurso a utilizar, con pleno respeto a los derechos de los menores y, entre ellos, el de asistencia jurídica independiente; que habrá de darse preferencia a los «sistemas restaurativos de resolución de conflictos e interactuación educativa» —expresión esta, por cierto, extrapolada del Protocolo básico de $2010^{132}$ —; que no podrán fijarse «restricciones» - propiamente, sanciones - de igual o mayor entidad a las previstas en la normativa en materia de responsabilidad penal del menor; y que su aplicación no podrá restringir el derecho de visitas del menor (art. 34.1.2 LOPJM) ni su derecho a remitir quejas a organismos independientes, en particular, al Ministerio Fiscal, juez y Defensor del Pueblo o defensorías autonómicas (art. 35.1 LOPJM) ${ }^{133}$.

\section{PROCEDIMIENTO PARA LA ADOPCIÓN DE ESTA MEDIDA}

Las importantes peculiaridades que presenta esta modalidad de acogimiento residencial exigían un procedimiento específico ${ }^{134}$, tal y como ha sido articulado en el nuevo art. 778 bis LEC, de modo paralelo al art. 763 del mismo cuerpo legal, relativo al internamiento no voluntario con trastorno psíquico ${ }^{135}$. Se trata de un procedimiento judicial de carácter contradictorio $^{136}$, dirigido a obtener la oportuna autorización judicial a la que, en todo caso, se supedita el ingreso en estos centros y que incluye una serie de garantías específicas para los menores, junto a otras adicionales. La reforma de 2015 ha omitido, sin embargo, toda referencia a la constitución del acogimiento residencial por parte del Administración que, a mi entender, ha de acompañar

131 Como advirtió, antes de la reforma de 2015, el Defensor del Pueblo (2009: 398).

132 Comisión Interautonómica de Directores Generales de Infancia (2010: 20).

133 Este derecho de los menores a formular quejas ha sido incorporado en 2015 a la LOPJM, de conformidad con las recomendaciones internacionales: Asamblea General de Naciones Unidas (1990: recomendación 76), Comité de Ministros del Consejo de Europa (2005: apdo. II, regla 14) y Comité de los Derechos del Niño de Naciones Unidas (2010: recomendación 42.c).

134 Según se puso de relieve en las comparecencias en la Comisión especial del Senado (acta de la sesión de 28 de marzo de 2011: 22-23).

135 Como señala, asimismo, la Fiscalía General del Estado (2016: 28).

136 De acuerdo con la Fiscalía General del Estado (2016: 53). 
necesariamente a la autorización judicial de ingreso, desde el momento en que al juez autorizante no se le atribuye complementariamente tal competencia ${ }^{137}$.

\subsection{La necesaria autorización judicial}

En atención a los arts. 778 bis.3 LEC y 26.3 LOPJM, la principal especialidad en este punto radica en la necesaria autorización judicial previa a que se supedita el ingreso de los menores en los centros de protección específicos, de modo coincidente con los internamientos por trastorno psíquico. Ello con una salvedad prevista, asimismo, para esta modalidad de internamiento: que razones de urgencia hagan necesaria la inmediata adopción de la medida, en cuyo caso se exige su ulterior ratificación judicial. Se dispensa así el mismo tratamiento a ambas modalidades de ingreso, lo que se justifica por su incidencia en los derechos fundamentales de sus correspondientes destinatarios y, entre ellos fundamentalmente, en su libertad personal. No obstante, obsérvese que mientras la autorización judicial —o, en su caso, la ratificación judicial—para el internamiento por trastorno psíquico se supedita a la ausencia del consentimiento del interesado ${ }^{138}$, la de ingreso de un menor en centro de protección específico se exige en todo caso; esto es, independientemente de que concurra o no su consentimiento, como clarifica la Circular FGE 2/2016 (Fiscalía General del Estado, 2016: 22). De este modo, la reforma de 2015 se ha hecho eco de las recomendaciones vertidas por el Comité de los Derechos del Niño de Naciones Unidas (2010) y, a nivel nacional, por el Defensor del Pueblo (2009) y la Fiscalía General del Estado (2010-2011) ${ }^{139}$, desvinculándose así del Protocolo básico (2010), donde la competencia para autorizar el ingreso

137 Nótese que la constitución del acogimiento residencial, a diferencia del familiar, no fue objeto de regulación en la reforma de 2015, lo que hubiese sido muy necesario ante la ausencia de una solución uniforme y debidamente pormenorizada sobre el particular en la legislación autonómica de protección de menores. De hecho, de tal contingencia dio cuenta, en fase del anteproyecto de 2014, el Consejo General del Poder Judicial (2014: 52), sin que se tomase en cuenta su recomendación en orden a la introducción de un régimen ad hoc. A partir de ahí, en defecto de previsión específica, las Entidades Públicas de protección de menores han adoptado la práctica de solicitar la autorización judicial de ingreso en centro específico, para, una vez obtenida esta, proceder a constituir el acogimiento residencial y delegar la guarda al director del centro a través de la oportuna resolución administrativa (fuente: técnicos del IASS).

138 Sobre este presupuesto, véase Calaza López (2007: 194-197).

139 Comité de los Derechos del Niño de Naciones Unidas (2010: recomendación 42.b), Defensor del Pueblo (2009: 394 y 407) y Fiscalía General del Estado (memoria 2010: 977 y Circular 2011: 56). En esta misma línea favorable a la intervención judicial se 
en tales centros se confería, de modo muy discutible, a la Entidad Pública tutora o guardadora de los menores, en línea con buena parte de la normativa autonómica de protección de menores ${ }^{140}$.

La competencia objetiva para autorizar el ingreso se atribuye al juzgado de primera instancia (art. 778 bis.2 LEC), como, por lo demás, la atinente a las restantes resoluciones judiciales en materia de protección de menores a que se refieren los arts. 778 ter y 779-780 de la ley rituaria civil —autorización de entrada en domicilio para la ejecución forzosa de medidas de protección de menores y oposición contra las resoluciones administrativas en materia de protección de menores-. En lo que atañe a la competencia territorial, se ha optado por atribuirla al juzgado del lugar donde radique el centro, opción esta que en principio tiene su razón de ser desde el momento en que, como regla, sus competencias van más allá de autorizar el ingreso, correspondiéndole también su control ulterior, así como acordar su cese (art. 778 bis.6 y 7 LEC), lo que requiere la existencia de una proximidad con el centro donde está ingresado el menor. No obstante, se ha prescindido de la contingencia relativa a la ausencia de centro, ya no solo en la localidad donde reside el menor, sino en la comunidad autónoma cuya Administración haya asumido su tutela o guarda, lo que no es infrecuente, habida cuenta de la tradicional escasez de centros de estas características, difícilmente subsanable, por lo demás, en atención a la DF 5a LO 8/2015 ya referida ${ }^{141}$.

pronunció, en fase del anteproyecto de 2014, el Consejo General del Poder Judicial (2014: 27).

${ }^{140}$ En concreto, la Comisión Interautonómica de Directores Generales de Infancia (2010: 6) solo contemplaba como excepción a esta regla que se tratase de centros «que utilicen habitualmente medidas de contención», en cuyo caso debería solicitarse por parte de la Administración autorización o, en su caso, ratificación judicial. En la legislación autonómica de protección de menores adopta la misma solución el art. 6.i.2 del Decreto 37/2004 de Castilla y León; con todo, son mayoría las normas que prevén exclusivamente la autorización administrativa de ingreso (por ejemplo, el art. 82.2 de la Ley 5/2014 de Castilla-La Mancha, el art. 133 de la Ley catalana 14/2010, el art. 10 del Decreto asturiano 48/2003 y el art. 7 del Decreto vasco 131/2008).

141 Ante esta contingencia (contemplada, sin embargo, en la legislación autonómica de protección de menores; por ejemplo, el art. 82.2 de la Ley 5/2014 de Castilla-La Mancha, el art. 96.8 de la Ley 14/2002 de Castilla y León y el art. 91.4 de la Ley $1 / 2006$ de la Rioja) y adicionalmente para facilitar la audiencia del menor y de sus progenitores o tutor, García Díez (2016: 11) estima más adecuada la competencia del juzgado del domicilio del menor, en línea con la posición defendida, en fase del anteproyecto de 2014, por el Consejo Fiscal (2014: 20). Por mi parte, considero que en el caso expuesto lo más razonable hubiera sido atribuir la competencia de ingreso 
En cualquier caso, conforme al principio de justicia rogada que rige en el proceso civil, dicha medida judicial solo opera a instancia de parte, reconociéndose legitimación a este respecto exclusivamente a la Entidad Pública tutora o guardadora y al Ministerio Fiscal (art. 778 bis.1 LEC y arts. 26.1 y 3.1 LOP$\mathrm{JM})^{142}$; no así, en cambio, a los progenitores que mantengan la patria potestad - o en su caso, autoridad familiar o responsabilidad parental—, como sucede en la situación de guarda administrativa, lo que no deja de ser discutible ${ }^{143}$.

Por lo que hace al concreto contenido de la resolución judicial —un auto- ${ }^{144}$, no se circunscribe a autorizar o, en su caso, denegar el ingreso, sino que, de ser favorable al mismo, habrá de pronunciarse sobre dos extremos adicionales, en aplicación del principio de proporcionalidad que rige esta medida: de una parte, sobre la posible adopción de medidas de seguridad y la limitación del régimen de visitas, comunicaciones y salidas (art. 26.3 LOPJM), lo que, a mi entender, viene a constituir una suerte de habilitación judicial para que el director del centro adopte excepcionalmente estas medidas; y de otra, sobre la obligación de la Entidad Pública y del director del centro de emitir el correspondiente informe periódico de seguimiento, al objeto de su debido control tanto por el propio juez como por el Ministerio Fiscal y, en su caso, acuerdo judicial de cese (art. 778 bis.6.1 LEC) ${ }^{145}$. Nada prevé, sin embargo, la legislación aplicable sobre la fijación de un plazo máximo de estancia en el centro en aras de una mayor seguridad jurídica ${ }^{146}$ ni sobre el carácter necesariamente motivado

al juez del lugar de domicilio del menor, como propone García Díez, ello sin perjuicio de que el ulterior control y cese corresponda al juez del lugar donde radica en centro, por las razones expuestas en texto.

142 Por lo que hace a la legitimación del Ministerio Fiscal, la Fiscalía General del Estado (2016: 41-42 y 56) recomienda su uso excepcional, «limitado a los casos de notoria pasividad o actuación manifiestamente errática en la adopción de medidas por la Entidad Pública», lo que requiere el examen por su parte del plan individual de protección del que debe estar provisto todo menor sujeto a acogimiento residencial ex art. 19 bis.1 LOPJM.

${ }^{143}$ Cuestiona, asimismo, esta falta de legitimación la Fiscalía General del Estado (2016: 21-22).

${ }^{144}$ En defecto de previsión expresa en el art. 778 bis LEC sobre la forma a adoptar por esta resolución judicial, de la lectura de la Circular 2/2016 FGE (30) parece desprenderse que se trata de un auto. Así lo entienden, igualmente, Martín Azcano (2015: 9) y García Díez (2016: 13-14).

145 Previsión esta, a mi entender, innecesaria, habida cuenta del carácter legal de esta obligación, en atención a lo dispuesto en los arts. 32.1 LOPJM y 174 CC.

146 Se ha obviado así la recomendación que, en fase del anteproyecto de 2014, hizo el Consejo Económico y Social (2014: 13). Señala, asimismo, esta contingencia Ferreirós Marcos (2017: 20). 
del auto ${ }^{147}$, como hubiera sido oportuno. Y es que, a mi entender, el juez autorizante deberá justificar la necesidad de este instrumento de protección por inexistencia de otro recurso menos restrictivo que permita atender adecuadamente al menor, en palabras del art. 778 bis. 4 in fine LEC $^{148}$. Por añadidura, el auto deberá basarse en el interés superior del menor, según resulta del art. 2 LOPJM, y, además, expresar el resultado y la valoración de la audiencia, conforme a lo dispuesto en el art. 9.3, 2a parte LOPJM ${ }^{149}$.

\subsection{Garantías reservadas al menor}

Una valoración muy positiva me merecen, asimismo, las garantías procesales específicamente reservadas al menor susceptible de potencial ingreso en uno de estos centros, en cuanto revelan el importante esfuerzo del legislador de adecuar el sistema español de protección de menores a la Convención sobre los Derechos del Niño de 1989 (art. 12), al Convenio Europeo sobre el Ejercicio de los Derechos de los Niños de 1996 (arts. 3 y 6) y a las Directrices del Comité de Ministros del Consejo de Europa sobre justicia adaptada a los niños de 2010 (apdo. I, reglas 1 a 5, 44 a 49 y 75 ). Así, el art. 778 bis.4 LEC reconoce a los menores, en primer lugar, el derecho a ser oídos - y escuchados, conforme al art. 9 LOPJM - por el juez que conoce del procedimiento, con el objeto de analizar su presunto problema de conducta — para cuyo examen existen dos pruebas adicionales: el examen judicial directo y el dictamen de un facultativo-, así como para conocer su opinión sobre esta medida ${ }^{150}$. En segundo término, y para el caso de que se autorice el ingreso, los menores tendrán derecho a ser informados sobre el mismo en formato accesible y adaptado a su edad y circunstancias (art. 778 bis.4, en relación con el art. 21

147 Advirtieron, igualmente, esta omisión, en fase del anteproyecto de 2014, el Consejo de Estado (2014: 35) y el Consejo General del Poder Judicial (2014: 35).

148 A este respecto, García Díez (2016: 14) indica que la motivación del auto de ingreso no solo constituye una exigencia constitucional ex art. 120.3 CE, sino una necesidad para garantizar un adecuado marco convivencial en estos centros.

149 De acuerdo con la Fiscalía General del Estado (2016: 30).

150 Se extrapolan aquí las afirmaciones vertidas por Calaza López (2007: 211) sobre internamiento por trastorno psíquico. Adviértase, por lo demás, que el derecho del menor a ser oído y escuchado debe interpretarse conforme a las previsiones del art. 9 LOPJM en su redacción dada en 2015, al objeto de su debida adecuación al art. 12 de la Convención sobre los Derechos del Niño de 1989 y la Observación general núm. 12 (2009) del Comité de los Derechos del Niño de Naciones Unidas sobre el derecho del niño a ser escuchado. 
bis.1.a LEC) $)^{151}$. Y por último, se les atribuye el derecho a recurrir en apelación el correspondiente auto judicial (art. 778 bis.5 LEC).

Este régimen tan garantista no ha venido acompañado, sin embargo, de una previsión específica acerca de la representación y la defensa del menor durante la tramitación del procedimiento, lo que exige acudir a las disposiciones generales que sobre este extremo contiene la LOPJM ${ }^{152}$. Me refiero a los arts. 2.5 y 10.2.e, que, en línea con el Convenio Europeo sobre el Ejercicio de los Derechos del Niño de 1996 (art. 9) y las Directrices del Consejo de Ministros del Consejo de Europa sobre justicia adaptada a los niños de 2010 (apdo. IV, regla 37), consagran el derecho de los menores a solicitar en los procedimientos que les afecten asistencia jurídica, así como el nombramiento de un defensor judicial, de existir conflicto de interés — como, entiendo, sucede en el caso aquí planteado - con sus representantes legales, ya sean los progenitores o tutor ordinario, o la Entidad Pública tutora ${ }^{153}$. De no ejercitar el menor este derecho, su defensa correrá a cargo del Ministerio Fiscal, cuya intervención es preceptiva de acuerdo con el art. 749.2 LEC $^{154}$.

\subsection{Garantías adicionales}

Junto a los derechos procesales reconocidos al menor, el art. 778 bis.4 LEC formula complementariamente una serie de garantías adicionales, coincidentes en buena medida con las previstas en el art. 763.3 de la misma ley para el internamiento por trastorno psíquico. La primera de ellas tiene que ver con las preceptivas audiencias de la Entidad Pública tutora o guardadora, de los progenitores o tutores "que ostentaran la patria potestad o tutela»" $\mathrm{y}$ adicionalmente

151 En cualquier caso, el contenido de este derecho de información del menor va más allá del mero auto de ingreso, ya que el art. 26.4 LOPJM dispone que los menores, en el momento de su ingreso en el centro, habrán de recibir información adaptada a su edad y circunstancias, pero necesariamente por escrito en este caso, tanto sobre el régimen interno del mismo, incluido el disciplinario, como sobre los derechos y deberes que les asisten y los medios de que disponen para formular peticiones, quejas y recursos.

152 De acuerdo con el Consejo de Estado (2014: 36) y la Fiscalía General del Estado (2016: 23-24).

153 En cualquier caso, el nombramiento de defensor judicial sólo procederá, siempre que los menores no hayan sido emancipados, pues, de estarlo, el art. 323 Cc les faculta para comparecer por sí solos en juicio.

154 De acuerdo con la Fiscalía General del Estado (2016: 25).

155 En mi opinión, y aquí me permito disentir de la Fiscalía General del Estado (2016: 29), la expresión «que ostentaran la patria potestad o tutela» permite considerar in- 
«de cualquier persona cuya comparecencia [el juez] estime conveniente o le sea solicitada» —entiéndase, especialmente del entorno sociofamiliar del menor-, a fin de obtener la información lo más completa posible sobre el menor. En segundo lugar, se requiere informe del Ministerio Fiscal sobre la justificación o no de la medida, a emitir previo examen del expediente de protección del menor $^{156}$. Y por último, se impone al juez la obligación de recabar dictamen de un facultativo por él designado ${ }^{157}$, sin perjuicio de que pueda practicar cualquier otra prueba, ya sea de oficio o instancia de parte.

\subsection{La necesaria ratificación judicial de los ingresos urgentes}

Como excepción a la regla de la autorización judicial previa, los arts. 26.3.2 LOPJM y 778 bis.3 LEC, en línea con el art. 763.1.2 LEC sobre el internamiento por trastorno psíquico, permiten «por razones de urgencia convenientemente motivadas» la inmediata adopción del ingreso en un centro de protección específico por parte de la Entidad Pública o del Ministerio Fiscal vía decreto ${ }^{158}$, si bien con la obligación de comunicarlo al juzgado de primera instancia del lugar donde radique el centro en un máximo de veinticuatro horas, al objeto de su debida ratificación. Tras la oportuna comunicación que deberá ir acompañada de la información disponible y del justificante del ingreso, no, sin embargo, de un informe psicosocial-, el juez, por su parte, tiene un plazo de 72 horas a contar desde que la reciba para ratificar dicha medida o no, en cuyo caso el ingreso devendrá ineficaz inmediatamente. Interesa señalar aquí, con la Fiscalía General del Estado (Circular 2/2016), que este plazo de 72 horas opera como límite máximo e improrrogable, so riesgo de vulnerar el derecho a la libertad personal del menor así ingresado ${ }^{159}$. Por tan-

cluida la situación de suspensión, toda vez que en este caso los progenitores o tutor propiamente siguen ostentando la titularidad de la patria potestad o tutela; no así, en cambio, la privación, como es obvio. Con todo, hubiera sido deseable una mayor claridad al respecto.

156 Según específica la Fiscalía General del Estado (2011: 34).

157 Nótese que esta concreta garantía en los términos en que está formulada dio lugar a posiciones contradictorias en fase de anteproyecto 2014. Así, mientras el Defensor del Pueblo (2014: 6) la valoró muy positivamente, el Consejo Fiscal (2014: 20) discrepó de su carácter preceptivo, en aras de la celeridad del proceso. Personalmente, lo considero un trámite muy necesario, aparte de defender su carácter multidisciplinar, según se ha argumentado en el epígrafe 4.2.

158 Según aclara la Fiscalía General del Estado (2016: 43).

159 En el mismo sentido se expresa Martín Azcano (2015: 8), invocando a tal efecto la jurisprudencia del Tribunal Constitucional vertida sobre el art. 763 LEC. 
to, vencido el plazo sin que el juez se haya pronunciado sobre la ratificación, quedará sin efecto el ingreso, si bien no desaparecerá la facultad del juez para autorizar ulteriormente si así se lo solicita la Entidad Pública o el Ministerio Fiscal, pudiendo, entre tanto, el menor ser ingresado provisionalmente en un centro de protección ordinario ${ }^{160}$. En cualquier caso, el procedimiento de ratificación habrá de respetar las mismas garantías que el dirigido a autorizar el ingreso, en atención a lo dispuesto en el art. 778 bis.4 LEC.

\subsection{Régimen de recursos}

Conforme al art. 778 bis. 5 LEC, el auto judicial de autorización o, en su caso, de ratificación del ingreso es recurrible en apelación. En concreto, están legitimados para interponer el oportuno recurso el menor afectado ${ }^{161}$, la Entidad Pública, el Ministerio Fiscal y los progenitores o tutores «que sigan teniendo legitimación para oponerse a las resoluciones en materia de protección de menores», expresión esta muy ambigua que requiere una aclaración, acudiendo para ello a los arts. 780.1.1 LEC y 172.2 Cc. Así, de la lectura conjunta de ambos preceptos parece resultar que, tratándose de menores en situación de guarda administrativa, los progenitores o tutores siempre tendrán legitimación para interponer el recurso que nos ocupa; en cambio, cuando los menores estén bajo tutela administrativa, la legitimación de aquellos queda circunscrita a los dos años siguientes a la notificación de la declaración de desamparo y ello de no haber sido privados de la patria potestad o, en su caso, removidos de la tutela, sino meramente suspendidos ${ }^{162}$.

En cualquier caso, según prevé el mismo precepto in fine, la interposición del recurso de apelación no tiene efecto suspensivo ${ }^{163}$, de tal manera que si el ingreso ha sido autorizado o ratificado judicialmente, el recurso contra esta decisión no dará lugar al cese de la medida, permitiéndose, en su lugar, su continuidad. Esta previsión se encuentra plenamente justificada, desde el momento en que esta modalidad de acogimiento residencial se configura como una medida de protección excepcional reservada a menores que se encuentran en una situación extrema y especialmente vulnerable, de tal modo

160 Fiscalía General del Estado (2016: 31-34), con base en la STC 141/2012, de 2 de julio, relativa al internamiento por trastorno psíquico.

161 Con necesaria designación de abogado y procurador, según precisa la Fiscalía General del Estado (2016: 26), con base en el art. 750.1 LEC.

162 Discrepo así de Vázquez-Pastor Jiménez (2016: 147) que reenvía exclusivamente al art. 172.2 CC.

163 Como recomendó en su momento la Fiscalía General del Estado (2011: 35). 
que necesitan un tratamiento inmediato, habiendo fallado todos los recursos intermedios.

\section{SUPERVISIÓN Y CONTROL}

El ánimo garantista de la reforma de 2015 se trasluce, igualmente, en el riguroso régimen de control que, en línea con los convenios y recomendaciones vertidos por diversas instancias internacionales ${ }^{164}$, ha reservado a esta modalidad de acogimiento residencial, dirigido tanto al seguimiento de los ingresos y sus resultados, como a la supervisión del adecuado funcionamiento de los centros de protección específicos.

Así, por lo que hace a la medida de ingreso del menor, corresponde a la Entidad pública su obligatoria revisión, en principio trimestralmente — salvo que el auto de ingreso haya fijado un plazo inferior en atención a la «naturaleza de la conducta» de que trae causa-, debiendo remitir al juez y al Ministerio Fiscal, con la misma periodicidad, un informe motivado de seguimiento que incluya las entradas en el libro registro de incidencias (art. 32 LOPJM, en relación con el art. 778 bis.6.1. y 2 LEC). De este mismo deber de información al juez y al Ministerio Fiscal sobre las circunstancias del menor y la necesidad de mantener la medida participa el director del centro (art. 778 bis.6. 1 y 2 LEC). Con ello se pretende evitar que el ingreso dure más tiempo que el estrictamente necesario ${ }^{165}$, toda vez que, una vez recibidos dichos informes, corresponde al juez decidir sobre la continuación o cese del ingreso (art. 778 bis.6.3 y 7 LEC), pero también verificar periódicamente que la medida se está aplicando con todas las garantías legales y el debido respeto a los derechos de los menores ${ }^{166}$, resultando esencial a tal fin la consulta del libro registro de incidencias, en cuanto recoge las medidas de seguridad objeto de aplicación (art. 27.4 LOPJM). En cualquier caso, esta intervención administrativa debe entenderse sin perjuicio del papel reservado por el art. $174 \mathrm{CC}$ al Ministerio Fiscal de «superior vigilancia» en materia de instrumentos públicos de protección de

${ }^{164}$ En particular, el art. 25 de la Convención sobre los Derechos del Niño de 1989, Asamblea General de Naciones Unidas (1990: reglas 72 a 73), Comité de Ministros de Consejo de Europa (2005: apdo. III, regla 8) y Comité de los Derechos del Niño de Naciones Unidas (2010: 42.d). Por añadidura, se han seguido las recomendaciones vertidas, a nivel nacional, por el Defensor del Pueblo (2009: 401) y la Comisión especial del Senado (Informe 2011: 163).

165 Como sostiene la Fiscalía General del Estado (2011:35) y, en la doctrina, Berrocal Lanzalot (2017: 292) y Vázquez-Pastor Jiménez (2016: 156).

166 En línea con el Consejo General del Poder Judicial (2014: 36-37). 
menores. Este papel se traduce, específicamente, en lo que atañe al acogimiento residencial, en el deber de vigilar «las decisiones de acogimiento residencial que se adopten» respecto del menor ingresado, con el necesario análisis de su proyecto educativo individualizado (art. 21.1.5 LOPJM) ${ }^{167}$.

Por añadidura, como rasgo común a todos los acogimientos residenciales, el art. 21.4 y 5 LOPJM contempla la supervisión de las condiciones de los centros de protección y de los procedimientos aplicados, atribuyéndose su inspección, con una periodicidad mínima de seis meses, a la Entidad Pública y al Ministerio Fiscal. Aunque necesario en todo caso, este control se revela esencial, a mi juicio, por lo que respecta a los centros de protección específicos, a fin de garantizar el cumplimiento del principio de especialización que inspira esta medida.

\section{CESE}

El carácter necesariamente temporal del recurso de protección exigía una previsión ad hoc sobre su cese, como es la formulada por duplicado en los arts. 26.5 LOPJM y 778 bis.7.2 LEC, preceptos que atribuyen exclusivamente esta decisión a la autoridad judicial, en discrepancia con lo dispuesto en el art. 763.4 LEC acerca del internamiento por trastorno psíquico ${ }^{168}$. Ahora bien, las expresiones empleadas por ambos preceptos para determinar el órgano judicial competente no resultan muy clarificadoras, además de no coincidentes, toda vez que mientras el art. 26.5, 2a parte LOPJM utiliza la expresión «órgano judicial que esté conociendo el ingreso", el art. 778 bis. 2 LEC se refiere meramente al «órgano judicial competente». Con todo, una interpretación lógica y sistemática de estos preceptos pasa por ponerlos en relación con el art. 776 bis. 6 LEC, de cuya lectura conjunta parece resultar que el cese corresponderá al juez que haya autorizado o ratificado el ingreso y se haya encargado de su supervisión ulterior, siempre que el menor permanezca en el mismo centro todo el tiempo que alcance la aplicación de la medida. En cambio, en caso de que el menor haya sido trasladado a otro centro de protección específico, "pasará a conocer del procedimiento» y, por tanto, de su control periódico y

167 Lo que, según clarifica García Díez (2016: 16), requiere su obligatoria remisión por el director del centro al Ministerio Fiscal, cuestión esta silenciada por el legislador.

$168 \mathrm{El}$ art. 763.4 LEC contempla la posibilidad de que los facultativos den de alta al internado cuando consideren que no es necesario mantener el internamiento, si bien con la obligación de comunicarlo al juez. Atribuir esta potestad al director del centro donde está ingresado el menor resultaría, a todas luces, excesivo a mi juicio. 
ulterior cese el juez del lugar donde esté ubicado el nuevo centro (art. 778 bis.6.4 LEC), lo que resulta plenamente justificado en aras del interés del menor. Por lo demás, el cese podrá ser acordado bien de oficio o a instancia de la Entidad Pública — entiéndase, tutora o guardadora - o del Ministerio Fiscal, debidamente fundamentada en un informe multidisciplinar (art. 778 bis.7.2 LEC $)^{169}$ y, en todo caso, previa audiencia del menor y del Ministerio Fiscal (art. 778 bis.6.3 LEC), no así en cambio de sus progenitores.

Nada se prevé, sin embargo, sobre el seguimiento ulterior de los menores y sus familias tras el cese del ingreso, lo que, a mi entender, hubiera resultado muy necesario para garantizar el éxito de la medida y, por ende, la plena reintegración familiar y social de sus destinatarios ${ }^{170}$.

\section{Bibliografía}

Aroca Montolío, C. (2013). La violencia de hijos adolescentes contra sus progenitores. Revista sobre la Infancia y la Adolescencia, 5, 12-30.

_ Paz Cánovas, L. y Alba Robles, J. L. (2012). Características de las familias que sufren violencia filioparental: un estudio de revisión. Educatio Siglo XXI, 30 (2), 231-254.

Berrocal Lanzarot, A. I. (2017). El acogimiento residencial en centros de protección específicos de menores con problemas de conducta en la Ley Orgánica 8/2015, de 22 de julio. En M. V. Mayor del Hoyo (dir.). El nuevo régimen jurídico del menor. La reforma legislativa de 2015 (pp. 267-308). Cizur Menor: Thomson Reuters-Aranzadi.

Boldova Pasamar, M. Á. (2011). ¿Queda algo del derecho de corrección de los progenitores en el ámbito penal? Revista de Derecho Penal y Criminología, 5, 55-95.

Calaza López, S. (2007). El proceso de internamiento no voluntario por razón de trastorno psíquico. Revista de Derecho UNED, 2, 175-225.

Claver Turiégano, E. (2017). Aproximación teórica a la violencia filioparental. Redes, 35 , 21-31.

De Palma del Teso, A. (2006). Administraciones públicas y protección de la infancia. Madrid: INAP.

Díez García, H. (2010). La protección de menores en conflicto social con conductas disruptivas, inadaptadas o antisociales (análisis de la atención a la peligrosidad social

169 En concreto, el art. 778 bis.7.2 LEC habla de «informe psicológico, social y educativo». No parece que en este caso sea necesaria la intervención de un psiquiatra, desde el momento en que la posible existencia de trastorno mental ya ha sido descartada en el momento de adoptarse la medida.

170 Se ha hecho así caso omiso a las recomendaciones del Defensor del Pueblo (2009: 27 y 408) y de los comparecientes en la Comisión especial del Senado (acta de la sesión de 13 de junio de 2011: 3 y 5). 
en las leyes autonómicas de protección de menores desde el prisma constitucional). Derecho Privado y Constitución, 24, 197-289.

Ferreirós Marcos, C. E. (2016). Ingreso en centros de protección para menores con problemas de conducta. Disponible en: https://bit.ly/2HZawX4.

- (2017). Ingreso en centros de protección para menores con problemas de conducta. Circular 2/2016 de la FGE. Disponible en: https://bit.ly/2rwDItB.

Galán Rodríguez, A. (2013). Recursos residenciales para menores seriamente disruptivos: aportaciones técnicas a un debate social e institucional. Papeles del Psicólogo, 34 (1), 23-31.

García Díez, M. (2016). Ingreso de menores con problemas de conducta en centros específicos. Disponible en: https://bit.ly/2KLT2eN.

García Pérez, C. L. (2018). Algunas cuestiones que plantea el Capítulo IV de la Ley Orgánica de protección jurídica del menor sobre el acogimiento residencial de menores con problemas de conducta. Revista Doctrinal Aranzadi Civil-Mercantil, 2, 1-29.

Gómez Aparicio, A. C. (2013). Autorizaciones judiciales de ingresos de menores en acogimientos residenciales en centros especializados. Asamblea. Revista Parlamentaria de la Asamblea de Madrid, 29, 275-292.

González-Álvarez, M., Morán, N., Gesteira, C. y García-Vera, C. (2011). Caracterización de los menores que agreden a sus padres. Psicopatología Clínica Legal y Forense, 11, 7-27.

Hurtado Yelo, J. J. (2009). Entre el derecho de corrección y el delito de malos tratos. Hacia la búsqueda de una solución intermedia. Actualidad Jurídica Aranzadi, 788, 1-9.

Llebaría Samper, S. (1990). Tutela automática, guarda y acogimiento de menores. Barcelona: Bosch.

Lozano Martínez, S., Estévez, E. y Carballo, J. L. (2013). Factores individuales y familiares de riesgo en casos de violencia filioparental. Documentos de Trabajo Social, 52, 239-254.

March, R. (2007). Claves para la intervención con menores acogidos en recursos residenciales, que presentan conductas problemáticas. Intervención Psicosocial, 7, 213-227.

Martín Azcano, E. M. (2015). El acogimiento residencial de menores con problemas de conducta en la Ley Orgánica 8/2015, de 22 de julio, de modificación del sistema de protección a la infancia y a la adolescencia. La Ley Derecho de familia, 6044, 1-15.

Mayor del Hoyo, M. V. (1999). La guarda administrativa como mecanismo de protección de menores en el Código civil. Granada: Comares.

Pereira Tercero, R. y Bertino Menna, L. (2009). Una comprensión ecológica de la violencia filioparental. Redes, 21, 69-90.

Pous de la Flor (2014). La controvertida eliminación de la facultad de corrección de los progenitores. Revista Crítica de Derecho Inmobiliario, 743, 1376-1401.

Sainz-Cantero Caparrós, B. (2014). El modelo común para la intervención con menores en riesgo y desamparo propuesto por el Anteproyecto de Ley de Protección de Infancia, Revista de Derecho Civil, 1 (4), 107-153.

Vázquez-Pastor Jiménez, L. (2016). El ingreso de menores con problemas de conducta en centros específicos de protección. Revista sobre la Infancia y Adolescencia, 11, 134-162. 


\section{Otras fuentes}

American Psychiatric Association. (2013). DSM-V Manual diagnóstico y estadístico de los trastornos mentales, $5^{\mathrm{a}}$ ed. Buenos Aires, etc.: Editorial Médica Panamericana.

Comisión Especial del Senado de Estudio de la Problemática de la Adopción Nacional y Otros Temas Afines (2011). Actas de la sesiones de 17 de marzo a 20 de septiembre de 2011. Disponibles en: https://bit.ly/2IrFkiw.

Comisión Especial del Senado de Estudio de la Problemática de la Adopción Nacional y Otros Temas Afines (2011). Informe de 20 de septiembre de 2011. BOCG. Senado. IX legislatura, 570 (26 de septiembre de 2011).

Comisión Interautonómica de Directores Generales de la Infancia. (2010). Protocolo básico de actuación con menores en centros y/o residencias con menores diagnosticados de trastornos de conducta. Disponible en: https://bit.ly/2KKlehQ.

Consejo de Europa. Comité de Ministros. (2005). Recomendación a los Estados miembros relativa a los derechos de los menores que viven en instituciones. Disponible en: https://bit.ly/2I3LTZu.

Consejo de Europa. Comité de Ministros. (2010). Directrices sobre justicia adaptada a los niños. Disponible en: https://bit.ly/2K96lo7.

Consejo Económico y Social (2014). Dictamen sobre el anteproyecto de ley orgánica complementaria de la ley de protección a la infancia. Disponible en: https://bit. ly/2Itv2hW.

Consejo Fiscal (2014). Informe al anteproyecto de ley orgánica complementaria de la ley de protección a la infancia. Disponible en: https://bit.ly/2I8TEcH.

Consejo General del Poder Judicial (2014). Informe al anteproyecto de ley orgánica de protección a la infancia.

Defensor del Pueblo. (2009). Informe sobre centros de protección de menores con trastornos de conducta y en situación de dificultad social. Madrid. Disponible en: https://bit.ly/2KMS1D5.

Defensor del Pueblo. (2014). Consideraciones sobre los anteproyectos de ley de protección a la infancia y de ley orgánica complementaria. Disponible en: https://bit. ly/2jMZJ3D.

Ministerio de Sanidad, Servicios Sociales e Igualdad. (2012). Estándares de calidad en acogimiento residencial (EQUAR). Disponible en: https://bit.ly/1fSuLNQ.

Ministerio de Sanidad, Servicios Sociales e Igualdad. (2015). Memoria del análisis del impacto normativo del anteproyecto de ley orgánica de modificación del sistema de protección a la infancia y la adolescencia. Disponible en: https://bit.ly/2wzM3mb.

Fiscalía General del Estado. (2000). Circular 1/2000, de 18 de diciembre, relativa a los criterios de aplicación de la Ley Orgánica 5/2000, de 12 de enero, por la que se regula la responsabilidad penal de los menores.

Fiscalía General del Estado. (2010). Circular 1/2010, de 23 de julio, sobre el tratamiento del sistema de justicia juvenil de los malos tratos de los menores contra sus ascendientes. Disponible en: https://www.fiscal.es.

Fiscalía General del Estado. (2010). Memoria de la Fiscalía General del Estado 2010. 
Fiscalía General del Estado. (2011). Circular 8/2011, de 16 de noviembre, sobre criterios para la unidad de actuación especializada del Ministerio Fiscal en materia de protección de menores.

Fiscalía General del Estado. (2016). Circular 2/2016, de 24 de junio, sobre el ingreso de menores con problemas de conducta en centros de protección específicos.

Fundación Amigó. (2017). Informe sobre violencia filioparental: una realidad invisible.

Naciones Unidas. Asamblea General. (1990). Resolución 45/113 reglas de las Naciones Unidas para la protección de los menores privados de libertad. Disponible en: https://bit.ly/2KOp61h.

Naciones Unidas. Comité de los Derechos del Niño. (2002). Observaciones finales a España de 13 de junio de 2002.

Naciones Unidas. Comité de los Derechos del Niño. (2006). Observación General núm. 8 sobre el derecho del niño a la protección contra los castigos corporales y otras formas de castigo, crueles o degradantes.

Naciones Unidas. Comité de los Derechos del Niño. (2009). Observación General núm. 12 sobre el derecho del niño a ser escuchado. Disponible en: https://bit.ly/2Iqoq4a.

Naciones Unidas. Comité de los Derechos del Niño. (2010). Observaciones finales a España de 3 de noviembre de 2010.

Observatorio de la Infancia en Andalucía. (2012). Centros de protección de menores en situación de desamparo que presentan trastornos de conducta en Andalucía. Sevilla: Junta de Andalucía. Disponible en: https://bit.ly/2IaIe8k.

Organización Mundial de la Salud. (1992). CIE 10 (Décima revisión de la clasificación internacional de las enfermedades: trastornos mentales y del comportamiento). Meditor: Madrid. 